\title{
KULEUVEN
}

\section{FACULTY OF ECONOMICS}

AND BUSINESS

An ex ante bidding model

to assess the incentive

creation capability of a

public-private partnership

pipeline

De Clerck D, Demeulemeester E. 


\title{
An ex ante bidding model to assess the incentive creation capability of a public-private
}

\section{partnership pipeline}

\author{
Dennis De Clerck ${ }^{1}$, Erik Demeulemeester \\ KU Leuven, Faculty of Economics and Business \\ Department of Decision Sciences and Information Management \\ Naamsestraat 69, B-3000 Leuven, Belgium \\ Tel: +32-16-32.67.58 / +32-16-32.69.72 \\ Fax: +32-16-32.66.24 \\ dennis.declerck@kuleuven.be \\ erik.demeulemeester@kuleuven.be
}

\begin{abstract}
The inherent risky nature of public-private partnerships requires contractors to make detailed and expensive project proposals. These high bidding costs are often seen as a burden for contractors to enter the playing field. Governments are seeking for ways to increase competition. It is a common belief that a project pipeline could succeed in triggering contractors' enthusiasm. The goal of this paper is to theoretically assess whether the pipeline serves as an effective tool to levy the barrier to entry. Therefore, a theoretical model and a simulation experiment that mimics the tendering process with heterogeneity in the bidders' cost structure are presented. In particular, the impact of a project pipeline on the ex ante bid preparation effort willingness and the targeted mark-ups is assessed. The Bayesian Nash equilibrium is heuristically approximated for scenarios with varying project characteristics. A statistical analysis of the experimental results approves that mark-ups are lower when more projects are included in the pipeline. As a consequence, this leads to fiercer price competition and a lower procurement cost for the government. Nonetheless, the incentive creation with respect to investment efforts is limited according to the experiment.
\end{abstract}

Keywords: public-private partnership procurement, multi-project bidding, ex ante strategy, simulation

\footnotetext{
${ }^{1}$ Corresponding author
} 


\section{Introduction}

This paper offers a theoretical approach in analyzing the procurement stage of a sequence of public-private partnership (PPP) projects. Because of its complexity and riskiness, long-term PPP projects require more preparation than traditional infrastructure projects. After an initial prequalification of interested consortia by the government, qualified concessionaires are invited for tender. The consortia have to prepare a proposal that will be submitted to the government which involves pre-tender research costs (e.g., consulting costs, design costs and market studies). Empirical evidence by KPMG (2010) reports average research costs of $1.5 \%$ to $2 \%$ of the total project cost. These pre-tender research costs or bidding costs are claimed to be a burden for the concessionaires because they do not guarantee to be awarded with the contract (Carrillo et al. 2008). Basically, each consortium will first decide how much money it is willing to invest in pretender research and secondly, the appropriate mark-up is determined. Due to the complexity, the high contingencies and the bidding costs, policy makers often argue that the market is too narrow in some jurisdictions, like in Australia, New Zealand or western European countries where often only two or three private entities show interest in particular high-risk PPPs.

Governments are seeking for ways to open up the playing field and incentivize the consortia to submit qualitative bid proposals and for possible entrants to penetrate the market. A recent KPMG report (2010) concludes with a set of guidelines to improve the efficiency of the PPP process and to reduce the bid costs which would in its turn stimulate the PPP market's attractiveness. Moreover, and supported by empirical evidence in Canada for instance, a pipeline of projects could increase the eagerness of consortia to enter and stay in the PPP market of a particular country (KPMG 2010). This pipeline reduces a consortium's risk of being unsuccessful, because instead of putting all one's eggs in one basket, a consortium can spread out its investments across different projects and it can offset former losses in future tenders. Due to the high cost and the extensive timeframe of PPP projects, the pipeline is usually of a limited nature. Governments change and long-term public budgets are hard to predict.

This paper extends the single-project PPP bidding model of De Clerck and Demeulemeester (2014) and translates the pipeline concept into a theoretical multi-project procurement model. The purpose is to determine an ex ante strategy for the bidders. This is useful for two reasons. Firstly, the tendering procedure is often time-consuming and therefore, contractors often have to undertake bid preparations for several projects at the same time. Moreover, organizing a 
consortium involves fixed costs that may be depreciated across multiple projects. Therefore, an ex ante strategy for a bidder is defined by a budgeted bid preparation effort (i.e., the investment decision) and a budgeted mark-up percentage (i.e., the mark-up decision). Furthermore, the bidders are heterogeneous in their experience levels. The past experience a bidder has obtained might lead to an increased ability to estimate the project cost on the one hand and to efficiency gains that result in a lower expected cost on the other hand. The contractors' pay-offs are obtained through simulation and the Bayesian Nash equilibrium is heuristically approximated. Subsequently, the scope is extended to the government to assess the reflection of the governmental policy mechanisms into the dynamics of the bidding behavior. On the one hand, public institutions are interested in the effect of the project pipeline on the procurement cost and, on the other hand, the impact of an investment reimbursement policy is investigated in a multiproject setting. De Clerck and Demeulemeester (2014) show in a single-project setting that compensations for the losers' investment efforts influence the bidding behavior and result into a more levelled playing field.

Next to its contribution to the PPP procurement literature, which only rarely considers competitive mechanisms, this study contributes to the procurement auction literature. It offers a methodological approach that favors the practical soundness of the model over limited analytical results that are subject to stringent assumptions. From a procurement auction perspective, this setting pioneers in combining the heterogeneity among bidders, the uncertainty in the project outcome and the possibility to shape the cost distribution in a multi-unit auction format without information revelation. The results offer a theoretical foundation for the introduction of policy guidelines that are in both the public as well as the private sector's interest. The triangulation through the qualitative validation and discussion of our findings guarantees the practical applicability and acted as a sounding board to identify the cases where our theoretical findings would be interfered by external assumptions or human factors.

The remainder of the paper is organized as follows. The next section highlights the bridge with traditional auction theory and maps the PPP procurement process within the field. Section 3 covers the analytical foundation and subsequently recapitulates and extends the algorithm that has been implemented for the equilibrium identification. The theoretical findings that result from the simulation output are statistically analyzed in Section 4. These outcomes are balanced against the qualitative findings and comments from practitioners in the global PPP field in Section 5. 
The paper concludes with some policy guidelines and highlights the extensions for further consideration.

\section{Literature review}

The study of the PPP competitive bidding model that is addressed in this paper is highly intertwined with auction theory. The multi-unit auction deserves particular interest in order to position the competitive PPP procurement model with a pipeline of projects. Multiple units might be auctioned simultaneously, so that bidders could bid on different packages of objects. Next to applications in electricity markets (Triki et al. 2005) and procurement markets (e.g., Chilean school meals in Catalán et al. 2009) on the public side, also the transport (Triki et al. 2014) and retail industry (Aissaoui et al. 2007) rely on the combinatorial auction mechanism. Well-supported by the growth of online auctions, the combinatorial auction design has received considerable attention within the operations research community (e.g., de Vries and Vohra 2003, Pekeč and Rothkopf 2003, Olivares et al. 2012). On the other hand, which may also be applicable in the PPP market, auctioning may be organized in a strictly sequential fashion. Within the sequential auction field, an important question relates to the price trend of the objects in the sequence. Although Weber (1983) proved that bids follow a Martingale in the case of an uncertain common value, the majority of auction studies claims that bid prices are declining. Early examples include Von der Fehr (1994) who studies auctions with a participation cost, Branco (1997) who considers complementarities between objects and Jeitschko (1999) for the case where the second auction only occurs with an exogenous probability. The declining price effect is usually attributed to the decreased competition in later stages due to capacity constraints. Engelbrecht-Wiggans (1994), however, relates the cost trend to the cost distribution of the stochastically equivalent objects. Besides the reduced competition, the author introduces a second effect that is related to the number of remaining chances to win in the case of a one unit demand. Additionally, Menezes and Monteiro (2004) claim that the trend depends on the synergies of the objects. Although we do not account for capacity constraints, our setting supports these findings from a procurement perspective in the sense that the lowest bidder wins the project opposed to the highest bidder in a traditional auction. The players' ex ante strategies consist of lower mark-ups for earlier projects in the pipeline, meaning that bidding is more aggressive in the early stages. 
The sequential auction has received increased attention and studies are generally categorized according to dimensions related to the objects' and bidders' characteristics. In order to guarantee the analytical manageability, a lot of studies limit themselves to a two-stage model (e.g., Branco 1997, Elmaghraby 2003, De Silva et al. 2005, Zeithammer 2009, Rei $\beta$ and Schöndube 2010, Jofre-Bonet and Pesendorfer 2014), while other formats look at Markov strategies in more extensive finite sequences (e.g., Katehakis and Puranam 2012, Takano et al. 2014) or account for an infinite timeframe (e.g., Oren and Rothkopf 1975, Zeithammer 2007, Hörner and Jamison 2008, Said 2011). In line with experience from practice, the PPP pipeline has a finite nature. This is due to the magnitude of the projects and the fact that government budgets have a limited time horizon. Our model develops an ex ante strategy, so that there are no proper sub-games for the different stages in the game and so that the strategy determination is simultaneous. Another object-related dimension concerns the relationship between the auctioned objects. The objects can have a homogeneous nature in the sense that they are perfect substitutes (Katzman 1999, Zeithammer 2009) or stochastically equivalent (Engelbrecht-Wiggans 1994, Rei $\beta$ and Schöndube 2010, Said 2011). Alternatively, synergies or the complementary feature of objects has proven to significantly influence strategic behavior (Branco 1997, Benoit and Krishna 2001, Menezes and Monteiro 2004, De Silva et al. 2005). The PPP model accounts for experience and learning effects, so that more competition could be expected in earlier stages of the game. An additional set of dimensions is related to the bidders. On the one hand, the capacity constraint diversifies the modeling approaches. The contributions of Milgrom and Weber (1982), EngelbrechtWiggans (1994), Elmaghraby (2003) and Reiß and Schöndube (2010) are limited to a single unit demand, while Katzman (1999), Jofre-Bonet and Pesendorfer (2003) and Katehakis and Puranam (2012) allow for the procurement of as many items as possible. Other models have constraints in the monetary capabilities (Pitchik 2009) or in the availability of man-hours (Takano et al. 2014). Last but not least, the research topics can be differentiated according to the identity of the bidders. Most papers deal with the same set of contractors and often take only two bidders into account. At the other end of the spectrum, Jofre-Bonet and Pesendorfer (2003), Yildirim (2004) and Said (2011) allow for the entry of new buyers. The PPP model of this paper reduces complexity in the sense that it only considers a limited number of suppliers and situations without capacity constraints. 
Furthermore, the PPP framework introduces three features that have only limitedly been studied in a theoretical fashion. Firstly, there is an important distinction between traditional auction theory and competitive bidding. An important aspect of competitive bidding is that bid prices are based on estimates of the project cost. This has been addressed in its earliest form by Friedman (1956). These cost estimates are subject to inaccuracies that also affect the bid price, as the bid price is usually correlated to the estimated cost (Naert and Weverbergh 1978, King and Mercer 1990, Takano et al. 2014). Hence, the inaccuracies are better grasped by the introduction of a mark-up that is applied to the estimated cost. Nevertheless, this complicates the winning probability calculations (King and Mercer 1990). This is in contrast with traditional auction theory that does not account for these uncertainties.

Another PPP peculiarity relates to the heterogeneity among bidders. From a practical perspective, it is important to look into discrepancies in the contractors' levels of experience. Maskin and Riley (2000) argue that asymmetric auctions are generally not tractable with analytical methods. In a sequential auction format, asymmetries could occur in a second auction because of differences in completion cost between the bidder that has won the first auction and the other players (Jofre-Bonet and Pesendorfer 2014). Empirical research has studied the complementarity of contracts, like Wolfram (1998) for sequential electricity contracts with startup prices, Anton and Yao (1987) in the defense sector and De Silva et al. (2005) for road infrastructure contracts. The asymmetry is an endogenous consequence. Nonetheless, our research will also consider exogenous heterogeneity, so that at each stage of the game, bidders may have different cost distributions. Rei $\beta$ and Schöndube (2010) start with differences in the project completion cost in the context of two sequentially tendered, stochastically equivalent projects and capacity constraints and describe the deviation from the standard independent private value auction. Moreover, the assumption of first order stochastic dominance is usually applied (Maskin and Riley 2000). The model of this paper relaxes this assumption. Being in an advantageous position has a double impact: the expected value of the cost distribution is lower, but also the variance of the cost distribution is smaller.

Finally, the PPP format is a form of an all-pay auction. Bidders invest money and resources to set up a project proposal. These investments could lead to more qualitative proposals, a decline in the expected project cost and a decrease in the project cost uncertainty. Empirical research acknowledges that bidding for PPPs is expensive (Carrillo et al. 2008, Chen and Doloi 2008) and 
is even perceived as a barrier to entry (KPMG 2010). In order to incentivize consortia, governments may reimburse bidders for the bidding cost. In a game-theoretical model, Ho (2008) studies the impact of a lump-sum reimbursement with homogeneous bidders. Ho argues against a compensation, but this is in contrast to De Clerck and Demeulemeester (2014) who consider heterogeneous bidders and favor compensations in a three-player setting with gaps in the experience levels. From an auction perspective, Arozamena and Cantillon (2002) expect fiercer competition in the presence of incentives and Rothkopf et al. (2003) show a decline in the procurement cost. Both studies look at single-shot auctions and do only consider cost benefits without uncertainty reductions.

In order to attain analytical results, assumptions simplify the often complex bidding contexts. Relaxations of these assumptions make the analysis very hard. King and Mercer (1988) acknowledge this issue in their review paper and claim that probabilistic strategies are hard to

study. Simulations highly contribute to the study of a complex environment and simultaneously allow for flexibility, which also benefits managerial decision makers. Mehlenbacher (2007) shows the increasing interest of multi-agent technology to study interactions among agents and strategies in complex environments. Recent applications of numerical simulations have proven to gain insights into complex auction and procurement formats (Cai and Wurman 2005, Farnia et al. 2013, Takano et al. 2014). Alternatively, laboratory experiments have also been a common means to analyze bidding behavior in a sequential procurement context (e.g., Brosig and Rei $\beta$ 2007, Cason et al. 2011).

\section{Methodology}

Combining contemporary PPP research and the view of practitioners from the public and private perspective has led to a framework with a manageable level of abstraction and that generalizes country- and sector-specific peculiarities. Due to the proliferation of decision variables and the non-linear nature of the problem, only a characterization of the equilibrium is possible. A simulation approach and algorithms to approximate the bidding behavior dynamics give interesting results. The model is consistent with De Clerck and Demeulemeester (2014), but the extensions are highlighted.

\subsection{The procurement model}

The bidders (also called the contractors in the remainder of the text) are usually consortia that consist of designers, subcontractors, maintenance companies, et cetera. The PPP model in this 
paper makes abstraction of the internal structure of the consortium or special purpose vehicle. Given is a project pipeline that has been clearly communicated by the government. The decision maker (i.e., the public party) determines the number of shortlisted bidders, which is usually between two and five depending on the market environment and the complexity of the project. We will assume that the number of bidders and their identity is constant over the pipeline. The shortlisted contractors will thus develop a project proposal with among other things project data, design details and the financial information. Due to the long-term time span, the magnitude and the entailed risk of PPPs, a lot of effort needs to be put into these proposals. These pre-tender research and development exertions come at a cost. Moreover, each contractor will determine the required mark-up that accounts for the aimed profit and the mitigation of risk. The project information and the bidding environment information that consists of the number of bidders and their respective competitive positions affect these decisions. After the proposals have been received, the government will make a decision based on the assessment of the cost and the quality of the submitted proposals.

\subsection{An ex ante strategy for the PPP pipeline}

The government initiates and communicates the project pipeline. The tendering processes are often long or overlapping and sometimes contractors have to make investments for future projects. Therefore, in this ex ante framework, there is no immediate information revelation so that contractors cannot change their strategy along the line which makes it a simultaneous game. This also means that his ex ante strategy is based on the expected beliefs whether he will win or lose a project before moving to the next project in the pipeline. Alternatively, a fully dynamic model would build a strategy pattern that prescribes the strategic behavior first for the initial project and would then determine the strategy for the second project for each possible outcome (i.e., for each possible winner) of the first project.

The purpose is to determine the influence of a project pipeline on the ex ante strategy determination. It is assumed that the number of bidders is expected to be the same over the course of the projects. Consequently, the initial experience levels of the shortlisted bidders are common knowledge. A sub-game $e=\left(e_{1}, e_{2}, \ldots, e_{P}\right)$ refers to the combination of experience levels and a discrete number of experience levels ranging from zero (i.e., no experience) to ten (i.e., maximum experience) is developed. In sub-game $e$ contractor $p$ determines his optimal strategy $s_{p}^{*}$ for the entire project pipeline with $Z$ projects. An ex ante strategy $s_{p}$ is composed of 
two decisions for each project $z \in\{1,2, \ldots, Z\}$ in the pipeline: an investment decision $i_{z}\left(s_{p}\right)$, that is expressed as a percentage of an initially set project cost base, and a mark-up decision $m_{z}\left(s_{p}\right)$, that is expressed as a percentage value and which is applied to the estimated project cost. The strategy for player $p$ is represented by a vector $s_{p}=\left(i_{1}\left(s_{p}\right), m_{1}\left(s_{p}\right), i_{2}\left(s_{p}\right), m_{2}\left(s_{p}\right), \ldots, i_{z}\left(s_{p}\right), m_{Z}\left(s_{p}\right)\right)$ with $i_{z}$ and $m_{z}$ respectively the investment percentage and mark-up percentage for project $z$. The investment level refers to the monetary effort that the contractor is willing to put into developing the project proposal. These costs could be lobbying costs, design and market study costs and working costs of the consortium. R\&D research and project management research believe in the dual impact of pretender investment: it leads to more accurate cost estimates, reducing the project risk, and innovations or efficiencies could directly decrease the expected project cost (Martzoukous and Zacharias 2013, Lippman et al. 2013). Each contractor simultaneously determines his optimal strategy so it is in our goals to identify the bidding equilibria. A (Bayesian) Nash equilibrium strategy profile $s^{*}=\left(s_{1}^{*}, s_{2}^{*}, \ldots, s_{P}^{*}\right)$ for sub-game $e$ refers to the combination of strategies for the players in which none of the bidders has an incentive to deviate from his current strategy choice $s_{p}^{*}$ given the strategy combination of his opponents $s_{-p}^{*}$. With $f_{p}($.$) the pay-off function for$ player $p$, this is mathematically expressed as: $\forall p, s_{p} \in S_{p}: f_{p}\left(s_{p}^{*}, s_{-p}^{*}\right) \geq f_{p}\left(s_{p}, s_{-p}^{*}\right)$.

Looking at the procurement process from a public angle, the government is the principal in shaping the bidding environment and is in fact able to influence the equilibrium bidding behavior. Firstly, it determines the number of shortlisted bidders that are invited for the tender. Secondly, the government is the decision maker and independently defines how much emphasis will be placed on the cost and the quality while assessing the proposals. Thirdly, which has already been tackled in a previous study, the government may decide upon the compensation policy towards the losing bidders. The public entity can reimburse a fraction of the investment cost of (some of) the losing bidders. Last but not least, which is the major subject of this paper, the government could launch several projects so that bidders believe that it is not a single-shot game, but that there are future opportunities available.

\subsection{Model assumptions}

The model assumptions from De Clerck and Demeulemeester (2014) are extrapolated to the issue of the project pipeline. The PPP market is in general heterogeneous. Practitioners from both 
the public as well as the private angle distinguish inexperienced entrants from mature, wellestablished incumbent consortia. In an academic vein, Oo et al. (2010) experimentally conclude that bidders' bidding behavior is diverse. Therefore, a first assumption concerns the introduction of an experience scale related to the number of projects a contractor has executed within a particular market.

Assumption 1: The bidding environment information that consists of the number of bidders and their respective experience levels is common knowledge. Winning a contract results in an experience level increase.

An important assumption for the strategic model is related to the exogeneity of the bidding environment. In the entire project pipeline, no new players enter the game and the same set of players are considered for each project. Nevertheless, winning a project may result in a knowledge and cost advantage in later tenders. Moreover, also the finite pipeline of projects is assumed to be common knowledge and, without taking experience and investment into account, all projects have a stochastically equivalent nature.

Assumption 2: The project pipeline is commonly known and each project has the same risk and cost structure. The same set of bidders is considered for the entire project pipeline.

A final assumption that is related to the dynamic modeling and that offers opportunities for extensions, concerns the budgetary and resource requirements.

Assumption 3: Each player is assumed to be capable of performing all projects in the pipeline and has sufficient resources at his disposal.

The remainder of the assumptions are related to the distributions and decision variables of each individual project in the pipeline. Uncertainty in the project outcome and the project risks are aggregated and translated into a single measure: the variance of the cost and associated bid probability distribution for each player. Complex or risky projects like toll roads or hospitals have wider distributions than social housing projects for instance. These distributions are dependent on the experience level of the bidder and the amount of money he has invested in research. On the one hand, it is expected that a consortium that has invested a lot in design or market studies is able to mitigate particular PPP risks and to more accurately estimate the project cost. Implementation-wise, it means that a contractor may narrow the cost probability distribution. Nevertheless, a bidder can only reduce the controllable part of the risk (e.g., project risk, demand risk), but not the uncontrollable part (e.g., force majeure risk, macroeconomic risk). 
On the other hand, experience and pre-tender investment will directly shift the distribution to the left, which results in a lower expected cost. The appropriation of experience may lead to efficiency gains and cost saving innovations may result from $R \& D$. An alternative interpretation, but with a slightly different implementation, is related to the government's decision mechanism that might be built on a cost/quality trade-off of the proposal. Quality could be defined in monetary terms and the government might reduce a bidder's price with a discount that represents the value the decision maker attributes to experience and to the quality of the proposal, related to a contractor's pre-tender investment. This is a variation on the cost adjustment implementation of Kostamis et al. (2009). This flexible approach validates the fact that the model's decision maker selects the lowest bidding contractor as the preferred bidder. Finally, risk neutrality is assumed, so that bidders want to optimize their expected pay-off.

Assumption 4: The complexity or risk of a project is translated into the variance of the cost distribution and consists of a controllable part and an uncontrollable part.

Assumption 5: The more experienced a player is and the more a contractor has invested in pretender research, the lower the variance of the cost probability distribution (knowledge impact assumption).

Assumption 6: The more experienced a player is and the more a contractor has invested in pretender research, the lower the expected project cost (direct cost assumption).

Assumption 7: All participants in the game are able to make accurate estimations of the parameters that are related to assumptions 4-6.

Assumption 8: The government selects the lowest bidding contractor. In case of a bidding cost reimbursement policy, bid compensations are equally credited to all losing bidders.

Assumption 9: Contractors maximize their expected pay-off.

Section 3.2 highlighted the strategy vector that is composed of the decision variables that reflect the strategic choices for each project in the pipeline. In order to reduce the complexity, the number of decisions has been kept to a minimum which results in two bidding models: a consistent strategy model (CSM) and a variable strategy model (VSM).

Assumption 10.1: The consistent strategy model (CSM) imposes that a contractor selects a single investment percentage and a single mark-up percentage that is applied to all projects in the pipeline. 
Assumption 10.2: The variable strategy model (VSM) allows a contractor to independently determine an investment percentage and a mark-up percentage for each project in the pipeline. The VSM allows for more flexibility, but the number of strategies explodes when more projects are included in the pipeline. Therefore, the constrained CSM model allows for longer pipelines, because a strategy in the CSM reflects an average investment and mark-up decision for the entire pipeline.

\subsection{Hypotheses}

The conclusions from consulting reports (KPMG 2010) and interviews with practitioners raise several hypotheses that are theoretically tested:

Hypothesis 1: In equilibrium, the investment percentages are expected to be higher if the number of projects in the sequence is greater both in the CSM as well as in the VSM.

Hypothesis 2: In equilibrium, the mark-up levels are expected to be decreasing if the number of projects in the sequence is greater both in the CSM as well as in the VSM.

Hypothesis 3: In equilibrium, the investment and mark-up choices vary for the different projects of the VSM.

Hypothesis 4: In equilibrium, the inhibiting effect of an increased number of players will be levelled off when the number of projects increases in both the CSM as well as in the VSM.

Hypothesis 5: Government compensation policies will be less essential in the creation of a more competitive market if there is a clear project pipeline in both the CSM as well as the VSM.

Hypothesis 6: The average expected project procurement cost for the government will decrease when the number of projects increases.

\subsection{The analytical background}

Given is a project pipeline with $Z$ projects, a $P$-player sub-game with initial experience levels $e=\left(e_{1}, e_{2}, \ldots e_{P}\right)$ and a strategy profile $s=\left(s_{1}, s_{2}, \ldots, s_{P}\right)$ in which each $s_{p}$ with $p \in\{1, \ldots, P\}$

refers to player $p$ 's strategy, expressed as a vector $s_{p}=\left(i_{1}\left(s_{p}\right), m_{1}\left(s_{p}\right), \ldots, i_{Z}\left(s_{p}\right), m_{Z}\left(s_{p}\right)\right)$. For this project pipeline and this strategy profile, the pay-off vector is dependent on the expected pay-off calculations of all projects in the pipeline. The outcome for the first project is straightforward, but the expectation of the second project will depend on who has won the first project, so that $P$ scenarios are created for the second project. For the third project, $P^{2}$ scenarios need to be considered. The expected pay-off for player $p$ in sub-game $e$ and a three-project environment with ex ante strategy profile $s$ is decomposed as follows: 


$$
\begin{aligned}
E\left[\pi_{p}(s \mid e)\right]= & \sum_{j=1}^{P} \sum_{k=1}^{P} q_{j}^{1}(s \mid e) * q_{k}^{2}\left(s \mid e, y_{j}^{1}=1\right) *\left(E\left[\pi_{p}^{1}(s \mid e)\right]+\delta_{1} E\left[\pi_{p}^{2}\left(s \mid e, y_{j}^{1}=1\right)\right]\right. \\
& \left.+\delta_{2} E\left[\pi_{p}^{3}\left(s \mid e, y_{j}^{1}=1, y_{k}^{2}=1\right)\right]\right)
\end{aligned}
$$

In this resulting expected pay-off function, some new terms have been introduced:

- $\quad q_{j}^{z}$ is the probability that player $j$ wins project $z$;

- $y_{j}^{z}$ is a binary variable that has value 1 if player $j$ has won project $z$ and indicates that the experience level of player $j$ is increased;

- $\quad \pi_{p}^{z}$ refers to the pay-off for player $p$ in the tender for project $z$;

- $\delta_{z-1}$ equals a discount factor to account for the time value of money.

De Clerck and Demeulemeester (2014) report the analytical pay-off calculation for a singleproject environment and most elements, apart from some notational differences, can be extrapolated to the multi-project environment. To determine the expected pay-off $E\left[\pi_{p}^{z}\left(s \mid e^{\prime}\right)\right]$ for player $p$ in project $z$, first define $e^{\prime}=\left(e_{1}^{\prime}, e_{2}^{\prime}, \ldots e_{P}^{\prime}\right)$ as the combination of intermediate experience levels for this particular sub-game, taking into account the winners of the previous projects, also called the history. Figure 1 serves as an example for the two-player case with normal distributions.

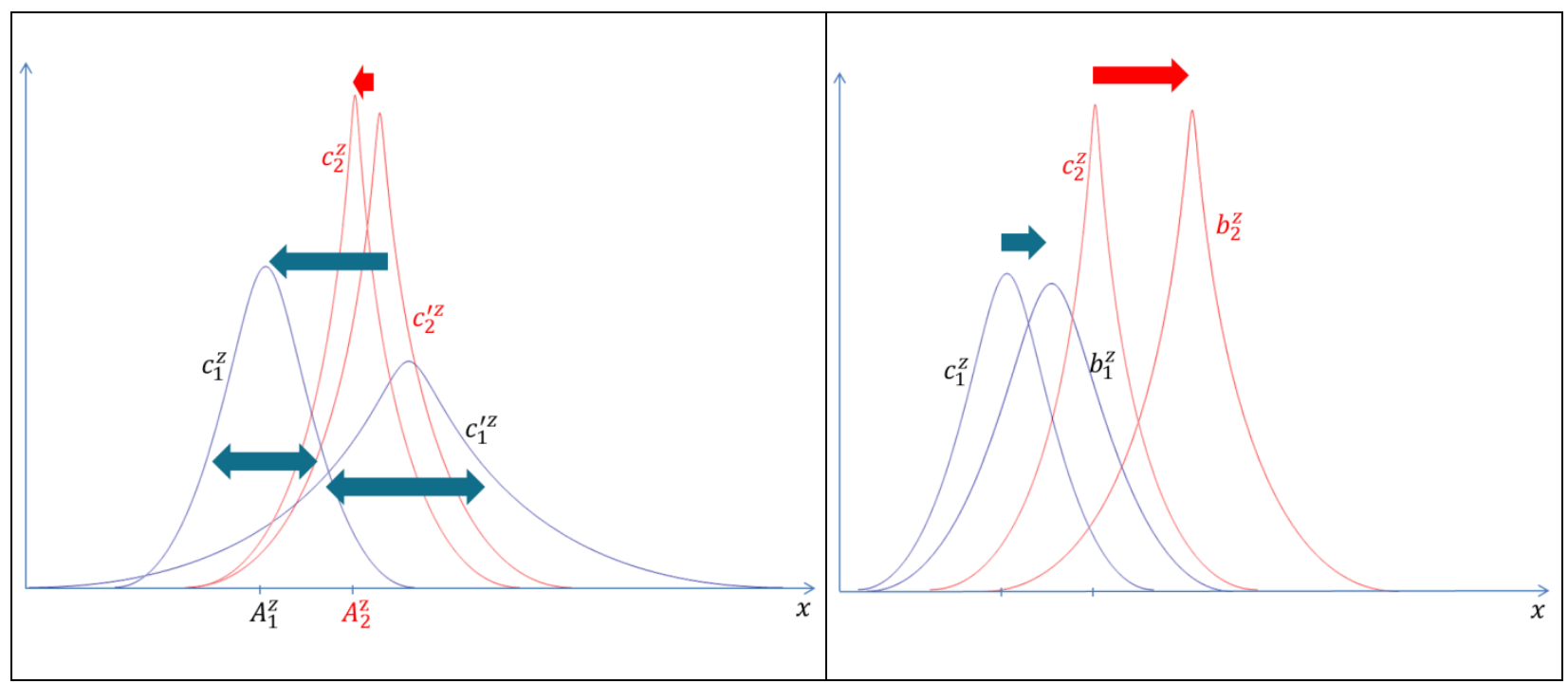

Figure 1: Illustration of the theoretical distributions. $c_{1}^{\prime z}$ and $c_{2}^{\prime z}$ are the cost probability distributions for two players, where player 2 has more experience than player 1. Player 1 applies a high investment choice and player 2 made a low investment choice and arrives in $c_{2}^{Z}$. The players apply their preferred mark-up choice (a low mark-up for player 1 and a high mark-up for player 2) arriving in the respective bid probability distributions $b_{1}^{Z}$ and $b_{2}^{Z}$. 
For a project with given risk parameters, the initial cost probability distribution $c_{p}^{\prime z}$ for player $p$ is a function of his experience level $e_{p}^{\prime}$. As a result of assumptions 5 and 6 , a more experienced bidder has an initial cost probability distribution $c_{p}^{\prime Z}$ with a smaller expected value and a smaller variance. Eventually, also the investment choice of the player modifies the probability distribution. Define $s^{Z}=\left(s_{1}^{Z}, s_{2}^{Z}, \ldots, s_{P}^{Z}\right)$ as the action profile with regard to project $z$ and $s_{p}^{Z}=\left(i_{z}\left(s_{p}\right), m_{z}\left(s_{p}\right)\right)$ the investment and mark-up choices with respect to project $z$. Combining the investment efforts $i_{z}\left(s_{p}\right)$ and the experience level $e_{p}^{\prime}$ results in the cost probability distribution $c_{p}^{z}$. The mark-up $m_{z}\left(s_{p}\right)$ is applied to an estimated cost that is generated from the cost probability distribution (Takano et al. 2014). Therefore, the mark-up choice shifts the cost probability distribution to the right, resulting in the bidding probability distribution $b_{p}^{z}$ and associated cumulative bidding distribution $B_{p}^{Z}$. The probability that project $z$ is attributed to player $p$ equals:

$$
q_{p}^{Z}\left(s \mid e^{\prime}\right)=\int_{-\infty}^{+\infty} b_{p}^{z}\left(x_{p}\right)\left[\prod_{k=1, p \neq k}^{P}\left(1-B_{k}^{Z}\left(x_{k}\right)\right)\right] d x_{p}
$$

Winning a tender results in receiving the proposed payment from the government and the actual cost and the monetary investment are subtracted to arrive at the pay-off. In the case of losing the tender, the pay-off equals the lost research cost, unless the government partly reimburses the losing bidders. Consequently, the expected pay-off for project $z$ in sub-game $e^{\prime}$ is:

$$
\begin{aligned}
E\left[\pi_{p}^{Z}\left(s \mid e^{\prime}\right)\right]= & q_{p}^{z}\left(s \mid e^{\prime}\right)\left(E\left[\widetilde{B_{p}^{z}} \mid p \text { has won }\right]-A_{p}^{z}\left(s_{p} \mid e_{p}^{\prime}\right)-i_{z}\left(s_{p}\right) \mu\right) \\
& -\left(1-q_{p}^{Z}\left(s \mid e^{\prime}\right)\right)(1-d) i_{z}\left(s_{p}\right) \mu
\end{aligned}
$$

with

- $A_{p}^{z}\left(s_{p} \mid e_{p}^{\prime}\right)$ the actual cost, taking into account that player $p$ has won. It equals the expected value of the cost probability distribution $c_{p}^{Z}$ that belongs to the winning contractor $p$. If $g: \mathbb{R}^{2} \rightarrow \mathbb{R}$ is the function that reflects the fractional direct cost impact that results from player $p$ 's experience level $e_{p}^{\prime}$ and the investment percentage $i_{z}\left(s_{p}\right)$ related to strategy $s_{p}$, then we have $A_{p}^{z}=\left(1+g\left(s_{p}, e_{p}^{\prime}\right)\right) \mu$;

- $\quad d$ the fraction of the investment cost that is reimbursed by the government;

- $\quad \mu$ a scaling factor; 
- the term $E\left[\widetilde{B_{p}^{z}} \mid p\right.$ has won $]$ that refers to the expected proposal that is made by player $p$ on the condition that he has won the tender with $\widetilde{B_{p}^{z}}$ a random variable from the bidding distribution $b_{p}^{Z}$.

The latter term of the expected pay-off function is calculated as a conditional expectation:

$$
E\left[\widetilde{B_{p}^{z}} \mid \widetilde{B_{p}^{Z}}<\widetilde{B_{k}^{z}}, \forall k \neq p\right]=\int_{-\infty}^{+\infty} x_{p} \frac{b_{p}^{z}\left(x_{p}\right) \prod_{k=1, p \neq k}^{P}\left(1-B_{k}^{Z}\left(x_{p}\right)\right)}{q_{p}^{Z}} d x_{p}
$$

Each contractor optimizes the expected pay-off for the entire project pipeline, which was formulated as $E\left[\pi_{p}(s \mid e)\right]$. This results in the following system of $2 * Z * P$ differential equations in the case of the VSM.

$$
\left\{\begin{array}{l}
\partial E\left[\pi_{p}\left(s^{*} \mid e\right)\right] / \partial i_{z}\left(s_{p}^{*}\right)=0 \\
\partial E\left[\pi_{p}\left(s^{*} \mid e\right)\right] / \partial m_{z}\left(s_{p}^{*}\right)=0 \quad \forall z \in\{1,2, \ldots, Z\}, \forall p \in\{1,2, \ldots, P\}
\end{array}\right.
$$

Under the CSM, a bidder applies the same strategy for each project in the pipeline (assumption 10.1), which would add the constraints that $i_{1}\left(s_{p}\right)=i_{2}\left(s_{p}\right)=\cdots=i_{Z}\left(s_{p}\right)$ and $m_{1}\left(s_{p}\right)=$ $m_{2}\left(s_{p}\right)=\cdots=m_{Z}\left(s_{p}\right)$, so that only two decision variables per player remain.

As more flexibility in the choices of the mark-up and investment percentage is allowed, the number of decision variables in the optimization problem rises exponentially in the VSM. Additionally, albeit feasible, the probability and pay-off calculations are computationally intensive. Moreover, finding a Nash equilibrium is generally acknowledged to be a hard problem, which is proven by the complexity studies of Conitzer and Sandholm (2003) and Daskalakis et al. (2006). Therefore, a discretization of the strategy field, a simulation approach and meta-heuristics to approximate a candidate Nash equilibrium are introduced in the subsequent sections.

\subsection{The procurement simulation}

In order to reduce computation times and in order to gain insight into the pay-off distributions, the simulation procedure of De Clerck and Demeulemeester (2014) is extended for the dynamic case. The inputs for the procedure to calculate the pay-off distribution consist of the initial experience vector $e=\left(e_{1}, e_{2}, \ldots, e_{P}\right)$ and the ex ante strategy profile $s=\left(s_{1}, s_{2}, \ldots, s_{P}\right)$. 
Recall that the ex ante strategy $s_{p}$ consists of the investment and mark-up choices for all projects in the pipeline. In the consistent strategy model (CSM), the bidder opts for a single investment percentage $i\left(s_{p}\right) \%$ and a mark-up percentage $m\left(s_{p}\right) \%$ that is applied to all projects. In the variable strategy model (VSM) though, choices may differ along the project line so that $s_{p}=$ $\left(i_{1}\left(s_{p}\right), m_{1}\left(s_{p}\right), \ldots, i_{Z}\left(s_{p}\right), m_{Z}\left(s_{p}\right)\right)$. For all the projects, the knowledge impact assumption is related to the variance of the cost and bidding distributions and is implemented as: $\sigma_{p}^{2}=$ $\sigma_{p}^{2}\left(e_{p}^{\prime}, i_{z}\left(s_{p}\right)\right)=\mu^{2}\left(\sigma^{2}+\left(\gamma_{i} e^{-\lambda_{i}\left(100 i_{z}\left(s_{p}\right)\right)}\right)^{2}+\left(\gamma_{e} e^{-\lambda_{e} e_{p}^{\prime}}\right)^{2}\right)$ with $e^{\prime}$ the intermediate experience levels in stage $z$ of the game. This formula introduces the project complexity parameters. $\gamma_{i}$ is the maximum impact of a lack of investment. The larger this parameter, the greater the importance of investment on the accuracy of the cost estimate. Equivalently, $\gamma_{e}$ is the maximum variance contribution of a lack of experience and quantifies the knowledge advantage of being experienced. $\lambda_{i}$ and $\lambda_{e}$ represent the respective associated growth parameters. $\mu$ is a scaling parameter and will be set to $€ 1,000,000$. The implementation of the cost impact assumption equivalently relies on diminishing scale effects and is given by: $g_{p}=g_{p}\left(e_{p}^{\prime}, i_{z}\left(s_{p}\right)\right)=\beta_{i} e^{-\mu_{i}\left(100 i_{z}\left(s_{p}\right)\right)}+\beta_{e} e^{-\mu_{e} e_{p}^{\prime}}$ with $\beta_{i}$ the innovation parameter related to the investment efforts and $\beta_{e}$ the efficiency parameter related to the experience.

In order to determine the pay-off distributions of a particular strategy profile, a user-defined number of iterations $m$ is performed. A single iteration passes through the entire project pipeline. The input for the first project is $e=\left(e_{1}, e_{2}, \ldots, e_{P}\right)$ and the investment and mark-up decisions $i_{1}\left(s_{p}\right)$ and $m_{1}\left(s_{p}\right)$ for the first project. Consider Gaussian cost and bidding distributions. The reference actual cost $\tilde{\mathrm{A}}^{1}$ is a random variable that is drawn from the distribution $N\left(\mu, \sigma_{u}^{2}\right)$ with $\mu=€ 1,000,000$ and $\sigma_{u}^{2}=(\mu * \sigma)^{2}$ and that is the same for all players. The final actual cost will be different, because it is related to the particular cost distribution of the winner of the tender. The expected project cost for $p$ results then from the linear transformation $\tilde{\mathrm{A}}_{p}^{1}=\tilde{\mathrm{A}}^{1}\left(1+g_{p}\right)$, which is set to the mean of the cost estimate function $c_{p}^{1}$ for player $p$. Hence, $c_{p}^{1}$ is a nested distribution (El Otmani and Maul 2009) of the form $N\left(\mu\left(1+g_{p}\right),\left(1+g_{p}\right)^{2}\left(\sigma_{u}^{2}+\sigma_{p}^{2}\right)\right)$. The contractor's estimated cost $\widetilde{C_{p}^{1}}$ is randomly selected from $c_{p}^{1}$ and eventually, a contractor applies 
the mark-up level $m_{1}\left(s_{p}\right)$, resulting in the bid: $\widetilde{B_{p}^{1}}=\left(1+m_{1}\left(s_{p}\right)\right) \widetilde{C_{p}^{1}}$. In summary, the form of the bidding probability distribution $b_{p}^{1}$ in this procurement simulation is:

$$
N\left(\mu\left(1+m_{1}\left(s_{p}\right)\right)\left(1+g_{p}\right),\left(1+m_{1}\left(s_{p}\right)\right)^{2}\left(1+g_{p}\right)^{2}\left(\sigma_{u}^{2}+\sigma_{p}^{2}\right)\right)
$$

The minimum of these simulated bids is the winning proposal and its pay-off is determined, where the actual bid is $\widetilde{A_{w}^{1}}$ for winner $w$. The losers' pay-offs equal the fraction of the pre-tender investments that are not reimbursed by the government. The winner's experience level needs to be increased, resulting in a new experience vector $e^{\prime}$ and the procedure is repeated for the second project and the resulting pay-offs are discounted (with the discount factor $\delta_{z-1}=\frac{1}{(1.05)^{z-1}}$ and $z$ the project number) and accumulated. The iteration finishes as soon as all projects from the pipeline have been tendered and then the next iteration starts.

Knowing how the pay-offs are calculated, we need to find the equilibrium strategy profile that generates equilibrium pay-offs for all players. The next section conceptually describes the approximation algorithm.

\subsection{Equilibrium approximation algorithm}

In order to reduce the complexity of the analytical model, a discretization of the strategies has been introduced. A strategy $s_{p}$ for player $p$ consists of all investment and mark-up choices for the projects in the pipeline. Instead of allowing an infinite number of strategies, discrete numbers of investment and mark-up percentages are studied. $I$ investment choices, $M$ mark-up choices, $P$ players and $Z$ projects result in $I * M$ strategies and $(I * M)^{P}$ strategy profiles in the CSM and $(I * M)^{Z}$ strategies and $(I * M)^{Z * P}$ strategy profiles in the VSM. In both models, the set of strategies for a player $p$ is referred to as $S_{p}$ and the set of strategy profiles is referred to as $S=S_{1} \times S_{2} \times \ldots \times S_{P}$. A strategy profile is given by $s=\left(s_{1}, s_{2}, \ldots, s_{P}\right)$ and $s \in S$ and the resulting pay-off vector by $f=\left(f_{1}(s), f_{2}(s), \ldots, f_{P}(s)\right)$.

The algorithm runs in a similar fashion as the strategy game in De Clerck and Demeulemeester (2014) and approximates the Nash equilibrium by determining a best response for player $p$ after first restricting the strategy space $S_{-p}$ for the competitors. Given the experience vector $e=$ $\left(e_{1}, e_{2}, \ldots, e_{P}\right)$, we want to determine the best response for player $p \in\{1,2, \ldots, P\}$ with experience level $e_{p}$. The algorithm will perform a prequalification of the strategies for all the $P-1$ competitors of player $p$. Initially, every competitor $q$ has a set of strategies $S_{q}$ and the 
heuristic reduces this set to a set of shortlisted strategies $R_{q}$ with $n$ elements. The prequalification is a two-stage process: a homogeneous stage to grasp the project characteristics in the shortlisted strategies and a heterogeneous stage to emphasize the competition aspect. After the prequalification, the strategy game algorithm is executed.

\subsubsection{Homogeneous stage}

Player $q$ with experience level $e_{q}$ has a set of strategies $S_{q}$ at his possession. The homogeneous stage resembles a knock-out tournament. A predefined number of rounds $r$ is set and the experience levels are set equal to $q$ 's experience level $e_{q}$ for all players. In the first round $P^{r}$ strategies are selected randomly and divided in $P^{r-1}$ groups of $P$ strategies. For each group of strategies, the average pay-offs are calculated according to the dynamic simulation of Section 3.6 and the best performing strategy continues to the next round where only $P^{r-1}$ strategies are remaining. The procedure continues until $P$ strategies remain and these are transferred to the set of shortlisted strategies $R_{q}$.

\subsubsection{Heterogeneous stage}

In this second stage, we keep the original experience vector $e$ and for each competitor $q$ an intermediate game is played in which all his strategies are assessed against random strategies for his opponents. In each iteration of the algorithm, random strategies from the complete set of strategies are selected for the competitors of player $q$. This results in the vector $s_{-q}$ which represents the strategy profile for the opponents of player $q$. Next, the expected pay-off and its variance is calculated for all the possible strategies from the set $S_{q}$ given the strategy profile $S_{-q}$ for his competitors and the experience vector $e$. In the next iteration, new strategies are randomly selected for player $q$ 's competitors. After a user-defined number of iterations $k_{1}$, the pay-off distribution for each strategy of player $q$ is derived and the best strategies are selected to be part of the shortlisted strategy list $R_{q}$.

\subsubsection{Strategy game algorithm}

When the shortlisting is performed for each competitor $q$ of player $p$, the final assessment stage will start. For each iteration of the algorithm, strategies are selected for the competitors of player $p$. For competitor $q$, these strategies are generated from the respective shortlisted set $R_{q}$. This results in a strategy profile $s_{-p}$. Player $p$ will now calculate the pay-off for each of the strategies of his set $S_{p}$. In the next iteration, new strategies are selected for the opponents of 
player $p$ and the pay-offs for this scenario are calculated. After $k_{2}$ iterations, the average over all scenarios is calculated for each of the strategies from the set $S_{p}$ and the best performing strategy for player $p$ is assumed to be a good proxy for the equilibrium strategy for this player.

4. Results

\subsection{Experimental setting}

The algorithm has been implemented in Microsoft Visual Studio 2010. Table 1 gives an overview of the determinants of the CSM and the VSM. The reported strategy outcomes refer to the equilibrium strategy response for the first player, with initial experience level $e_{1}$, of the experience vector $e=\left(e_{1}, e_{2}, \ldots, e_{P}\right)$. We will refer to the vector $e_{-1}=\left(e_{2}, \ldots, e_{P}\right)$ as the bidding situation for which we determine the equilibrium response of player 1 .

\begin{tabular}{lcc}
\hline & Consistent strategy model & Variable strategy model \\
\hline Number of investment levels & 11 & 6 \\
\hline Investment levels & $0 \%, 1 \%, 2 \%, \ldots, 10 \%$ & $0 \%, 2 \%, 4 \%, \ldots, 10 \%$ \\
\hline Number of mark-up levels & 51 & 6 \\
\hline Mark-up levels & $0 \%, 1 \%, 2 \%, \ldots, 50 \%$ & $0 \%, 10 \%, 20 \%, \ldots, 50 \%$ \\
\hline Number of players & $2,3,4$ & 2,3 \\
\hline Experience levels & $0,2,4,6,8,10$ & $0,2,4,6,8,10$ \\
\hline Number of projects & $1,2,3,4,5$ & $1,2,3$ \\
\hline
\end{tabular}

Table 1: Model characteristics

While the VSM allows greater flexibility, environments with more players and more projects inhibit the accuracy of the suggested equilibrium. However, in that case, the more manageable CSM could bring solace. In the experiment, different values for the model parameters are tested. Each combination of the parameter settings is called a scenario. The ex ante strategy equilibrium outcomes are compared for each scenario when the number of projects in the pipeline is increased. Consequently, the outcomes consist of paired observations and the paired samples ttest is used to study the differences. Three assumptions are important for the paired t-test: random sampling, normal distribution of the response variables and interval or ratio data. The paired t-test is rather robust for the normal distribution assumption. However, we are dealing with experimental data with only a limited number of discrete strategies and one should be careful for applying the parametric paired t-test. Therefore, the equivalent non-parametric Wilcoxon signed rank test has been used, but the findings are identical. In this set-up with discrete strategies and unique strategy equilibria, marginal effects will not be revealed. The results are divided in two parts. Section 4.2 defines a base case and focuses on the interaction between government policies (i.e., the number of projects and the bid cost reimbursement) and 
the investment-related project risk. Section 4.3 adds changes in the other model parameters of the VSM and reports the results of an extensive parameter sensitivity study. Table 2 lists the parameter values.

\begin{tabular}{clll}
\hline Parameter & Interpretation & $\begin{array}{l}\text { Values } \\
\text { (Section 4.2) }\end{array}$ & $\begin{array}{l}\text { Values } \\
\text { (Section 4.3) }\end{array}$ \\
\hline$\sigma$ & Uncontrollable project risk & 0.05 & 0.05 \\
\hline$\gamma_{e}$ & Maximum risk impact of a lack of experience & 0.05 & $0.05,0.1$ \\
\hline$\gamma_{i}$ & Maximum risk impact of a lack of investment & $0.1,0.2$ & $0.05,0.1,0.2$ \\
\hline$\lambda_{e}$ & Experiential learning rate & 0.25 & 0.25 \\
\hline$\lambda_{i}$ & Investment learning rate & 0.25 & 0.25 \\
\hline$\beta_{e}$ & Experiential cost disadvantage & 0.1 & $0.05,0.1$ \\
\hline$\beta_{i}$ & Investment cost disadvantage & 0.05 & 0.05 \\
\hline$\mu_{e}$ & Experiential cost decrease rate & 0.25 & 0.25 \\
\hline$\mu_{i}$ & Investment cost decrease rate & 0.25 & 0.25 \\
\hline$d$ & Government compensation level & $0,0.1,0.2, \ldots, 0.9$ & $0,0.3,0.6,0.9$ \\
\hline$\delta_{z}$ & Discount rate & $1 / 1.05$ & $1 / 1.05$ \\
\hline
\end{tabular}

Table 2: Parameter values used in the models

\subsection{Base case analysis}

Motivated by the practical importance of the assessment of governmental policies, this section looks into the impact of the introduction of extra projects and bid cost reimbursements in a lowrisk and high-risk base case scenario. For a high-risk PPP project, our experimental design uses a value for the $\gamma_{i}$ parameter of 0.20 and for the low-risk base case, this value is set to 0.10 . For the development of this base-case scenario, we opted for the assumptions that investment has mainly a knowledge impact and that experience has a cost impact.

\subsubsection{Consistent strategy model}

Table 3 reports the average investment and mark-up differences over all scenarios in the CSM experiment with the number of projects going from one to five. Recall that in the CSM the action choice is said to be stable for the entire pipeline which is a quite conservative approach. Concerning the investment levels, there is statistical significance in favor of decreasing investments in the four-player case, but the economic significance is little. Additionally, the results show a significant positive investment impact for three players in the low-risk base case. This result is mainly attributed to a $0.11 \%(\mathrm{p}=0.04)$ and a $0.41 \%\left(\mathrm{p}=1.9 * 10^{-10}\right)$ average investment raise by inexperienced players when moving from a single-project to, respectively, a two- and a five- project pipeline. Furthermore, extra projects lead to decreasing mark-up percentages for all players in two- and three-player environments in the CSM, but the four-player result is ambiguous (Table 3 ). 


\begin{tabular}{|c|c|c|c|c|c|c|}
\hline CSM & $\begin{array}{c}\Delta \text { in } \% \\
\text { (p-value) }\end{array}$ & $\gamma_{i}$ & $Z=2$ & $Z=3$ & $Z=4$ & $Z=5$ \\
\hline \multirow{4}{*}{2 players } & \multirow{2}{*}{ Investment } & 0.10 & $\begin{array}{c}0.0194 \\
(0.6920) \\
\end{array}$ & $\begin{array}{l}-0.0139 \\
(0.7618) \\
\end{array}$ & $\begin{array}{l}-0.0750 \\
(0.1036) \\
\end{array}$ & $\begin{array}{l}-0.0056 \\
(0.9061) \\
\end{array}$ \\
\hline & & 0.20 & $\begin{array}{c}-0.025 \\
(0.6058)\end{array}$ & $\begin{array}{c}0.0139 \\
(0.7643)\end{array}$ & $\begin{array}{c}0.0222 \\
(0.6320)\end{array}$ & $\begin{array}{c}0.0167 \\
(0.7155)\end{array}$ \\
\hline & \multirow{2}{*}{ Mark-up } & 0.10 & $\begin{array}{c}-0.4444 * * * \\
(0.0010)\end{array}$ & $\begin{array}{c}-0.7083^{* * *} \\
\left(5.5^{*} 10^{-7}\right)\end{array}$ & $\begin{array}{c}-0.8333 * * * \\
\left(5.1 * 10^{-9}\right)\end{array}$ & $\begin{array}{c}-0.9583^{* * *} \\
\left(2.4 * 10^{-10}\right)\end{array}$ \\
\hline & & 0.20 & $\begin{array}{l}-0.6389 * * * \\
\left(4.65 * 10^{-5}\right)\end{array}$ & $\begin{array}{l}-0.9722 * * * \\
\left(7.82 * 10^{-10}\right)\end{array}$ & $\begin{array}{c}-1.125 * * * \\
\left(1.47 * 10^{-13}\right)\end{array}$ & $\begin{array}{l}-1.3056^{* * *} \\
\left(3.04 * 10^{-15}\right)\end{array}$ \\
\hline \multirow{4}{*}{3 players } & \multirow{2}{*}{ Investment } & 0.10 & $\begin{array}{c}0.0191 \\
(0.6272)\end{array}$ & $\begin{array}{c}0 \\
(1)\end{array}$ & $\begin{array}{c}0.0587 * * \\
(0.0170)\end{array}$ & $\begin{array}{c}0.0627 * * \\
(0.0138)\end{array}$ \\
\hline & & 0.20 & $\begin{array}{l}-0.0063 \\
(0.8349)\end{array}$ & $\begin{array}{l}-0.0341 \\
(0.2794)\end{array}$ & $\begin{array}{c}0.0317 \\
(0.3214)\end{array}$ & $\begin{array}{c}0.0429 \\
(0.1865)\end{array}$ \\
\hline & \multirow{2}{*}{ Mark-up } & 0.10 & $\begin{array}{c}-0.5476^{* * * *} \\
\left(2.6 * 10^{-8}\right) \\
\end{array}$ & $\begin{array}{l}-0.8691 * * * \\
\left(<2.2 * 10^{-16}\right)\end{array}$ & $\begin{array}{l}-1.1468 * * * \\
\left(<2.2 * 10^{-16}\right)\end{array}$ & $\begin{array}{l}-1.4286^{* * * *} \\
\left(<2.2 * 10^{-16}\right) \\
\end{array}$ \\
\hline & & 0.20 & $\begin{array}{l}-0.2063 \\
(0.3225)\end{array}$ & $\begin{array}{c}-0.4722 * * \\
(0.0375)\end{array}$ & $\begin{array}{l}-1.1349 * * * \\
\left(2.35 * 10^{-6}\right)\end{array}$ & $\begin{array}{c}-1.4365 * * * \\
\left(6.31 * 10^{-9}\right)\end{array}$ \\
\hline \multirow{4}{*}{4 players } & \multirow{2}{*}{ Investment } & 0.10 & $\begin{array}{c}-0.0515 * * * \\
(0.0002) \\
\end{array}$ & $\begin{array}{c}-0.0378 * * * \\
(0.0057) \\
\end{array}$ & $\begin{array}{c}-0.0372 * * * \\
(0.0070)\end{array}$ & $\begin{array}{c}-0.0491 * * * \\
(0.0004)\end{array}$ \\
\hline & & 0.20 & $\begin{array}{l}-0.0301 \\
(0.1342) \\
\end{array}$ & $\begin{array}{c}0.0146 \\
(0.4776) \\
\end{array}$ & $\begin{array}{c}0.0024 \\
(0.9081) \\
\end{array}$ & $\begin{array}{c}0.0304 \\
(0.1414) \\
\end{array}$ \\
\hline & \multirow{2}{*}{ Mark-up } & 0.10 & $\begin{array}{l}0.3646^{* * * *} \\
\left(4.7 * 10^{-5}\right)\end{array}$ & $\begin{array}{c}0.3125^{* * * *} \\
(0.0006)\end{array}$ & $\begin{array}{c}0.2946 * * * \\
(0.0017)\end{array}$ & $\begin{array}{l}0.2307 * * \\
(0.0158)\end{array}$ \\
\hline & & 0.20 & $\begin{array}{c}0.0506 \\
(0.7493)\end{array}$ & $\begin{array}{l}-0.2083 \\
(0.2013)\end{array}$ & $\begin{array}{l}-0.2798^{*} \\
(0.0939)\end{array}$ & $\begin{array}{c}-0.5804 * * * \\
(0.0006)\end{array}$ \\
\hline
\end{tabular}

Table 3: Increase (+) or decrease (-) in the investment and mark-up percentages, with associated p-values for the two-sample t-test for the CSM, with respect to a single-project environment.

In a single-project context, the mark-up trend was negatively correlated with the experience level for the three- and four-player setting and slightly positive when two players are competing. The sign of this trend remains unchanged with the introduction of additional projects, but the slope changes, as mark-up responses to the longer pipeline vary with respect to the experience levels. In general, the inexperienced bidder makes the largest mark-up reduction.

The CSM experiment also tests different government compensation levels. From practice and from De Clerck and Demeulemeester (2014), we learn that compensations have the most prospering results for high risk projects in three-player settings. According to the experiments, the response to the introduction of compensations is the same, regardless of the number of projects in the pipeline. Two-player results show a significant increase in investment, but also a slight increase in mark-ups when compensations are included. The three-player environment indicates an upward investment trend and a significant downward mark-up trend, while compensations have a convex investment impact and a concave mark-up impact in the four- 
player case, so that only excessively high and costly compensations have a positive effect. The interaction between the number of projects and the government compensation is only significant in the three-player case of the $\operatorname{CSM}$ ( $\mathrm{p}=0.04$ for investment and $\mathrm{p}=1.7 * 10^{-5}$ for mark-up) meaning that lower compensations already lead to a drop in the mark-ups, making the market more competitive.

\subsubsection{Variable strategy model}

The VSM adds complexity, so only a limited horizon of at most three projects has been studied. Tables 4 and 5 summarize the results for differences in the investment and mark-ups for the first project of the $Z$-project pipeline and for the averages over the given pipeline. The twoplayer case supports the hypothesis of the investment increase for the first project in a twoproject pipeline, but looking at the averages only the increase in the high-risk environment is significant. The effects are more outspoken for inexperienced bidders. Moreover, significance disappears in a three-project environment. An explanation could be that the bidder who determines the ex ante strategy has a great belief in at least winning one project and in this vein counts on gained experience for which he does not need to invest now. Also for the mark-up change, the drop is more significant for the first project.

\begin{tabular}{|c|c|c|c|c|c|c|}
\hline \multirow[t]{2}{*}{ VSM } & \multirow{2}{*}{$\begin{array}{c}\Delta \text { in } \% \\
\text { (p-value) }\end{array}$} & \multirow[t]{2}{*}{$\gamma_{i}$} & \multicolumn{2}{|c|}{$\begin{array}{c}\text { (a) First project w.r.t. } \\
Z Z=1\end{array}$} & \multicolumn{2}{|c|}{$\begin{array}{c}\text { (b) Average of pipeline } \\
\text { w.r.t. } Z=1\end{array}$} \\
\hline & & & $Z=2$ & $Z=3$ & $Z=2$ & $Z=3$ \\
\hline \multirow{4}{*}{2 players } & \multirow{2}{*}{ Investment } & 0.10 & $\begin{array}{l}0.1611^{* *} \\
(0.0158)\end{array}$ & $\begin{array}{c}0.0556 \\
(0.5236) \\
\end{array}$ & $\begin{array}{c}0.0778 \\
(0.1565) \\
\end{array}$ & $\begin{array}{c}0.1000 \\
(0.1489) \\
\end{array}$ \\
\hline & & 0.20 & $\begin{array}{l}0.1056^{*} \\
(0.0970)\end{array}$ & $\begin{array}{l}-0.0556 \\
(0.5428)\end{array}$ & $\begin{array}{l}0.125 * * \\
(0.0230)\end{array}$ & $\begin{array}{c}0.1037 \\
(0.1405)\end{array}$ \\
\hline & \multirow{2}{*}{ Mark-up } & 0.10 & $\begin{array}{l}-2.0278^{* * *} \\
\left(<2.2 * 10^{-16}\right)\end{array}$ & $\begin{array}{l}-5.0556^{* * *} \\
\left(<2.2 * 10^{-16}\right)\end{array}$ & $\begin{array}{l}-1.2222 * * * \\
\left(1.25 * 10^{-9}\right)\end{array}$ & $\begin{array}{l}-2.2963 * * * \\
\left(4.12 * 10^{-14}\right)\end{array}$ \\
\hline & & 0.20 & $\begin{array}{l}-4.1944 * * * \\
\left(<2.2 * 10^{-16}\right)\end{array}$ & $\begin{array}{l}-6.1111 * * * \\
\left(<2.2 * 10^{-16}\right)\end{array}$ & $\begin{array}{l}-2.6667 * * * \\
\left(<2.2 * 10^{-16}\right)\end{array}$ & $\begin{array}{l}-3.8148 * * * \\
\left(<2.2 * 10^{-16}\right)\end{array}$ \\
\hline
\end{tabular}

Table 4: Increase (+) or decrease (-) in investment and mark-up percentages, with associated p-values. The single-project strategy is compared with (a) the choices for the first project of the pipeline and with (b) the average choices of the entire pipeline.

In the three-player environment, the introduction of an extra project does not seem to guarantee prospering results: an investment decrease is expected for highly complex projects, together with a mark-up increase. Nevertheless, this result is mainly caused by players with $e_{p}=\{0,2\}$, which deviates from the CSM results where an increase was reported for long pipelines. 


\begin{tabular}{|c|c|c|c|c|}
\hline \multirow[t]{2}{*}{ VSM } & \multirow{2}{*}{$\begin{array}{c}\Delta \text { in } \% \\
(\mathrm{p}-\text {-value })\end{array}$} & \multirow{2}{*}{$\gamma_{i}$} & $\begin{array}{l}\text { (a) First project w.r.t. } \\
\qquad Z=1\end{array}$ & $\begin{array}{c}\text { (b) Average of pipeline } \\
\text { w.r.t. } Z=1\end{array}$ \\
\hline & & & $Z=2$ & $Z=2$ \\
\hline \multirow{4}{*}{3 players } & \multirow{2}{*}{ Investment } & 0.10 & $\begin{array}{c}0.0413 \\
(0.1959)\end{array}$ & $\begin{array}{c}0.0325 \\
(0.2330)\end{array}$ \\
\hline & & 0.20 & $\begin{array}{c}-0.1048 * * * \\
(0.0045)\end{array}$ & $\begin{array}{c}-0.07619^{* *} \\
(0.0196)\end{array}$ \\
\hline & \multirow{2}{*}{ Mark-up } & 0.10 & $\begin{array}{l}-1.5000^{* * * *} \\
\left(<2.2 * 10^{-16}\right)\end{array}$ & $\begin{array}{l}-0.6865^{* * *} \\
\left(1.76^{*} 10^{-11}\right)\end{array}$ \\
\hline & & 0.20 & $\begin{array}{c}0.5968 * * \\
(0.0119)\end{array}$ & $\begin{array}{l}0.5595 * * * \\
(0.0039)\end{array}$ \\
\hline
\end{tabular}

Table 5: Increase (+) or decrease (-) in investment and mark-up percentages, with associated p-values. The single-project strategy is compared with (a) the choices for the first project of the pipeline and with (b) the average choices of the entire pipeline.

Besides, the VSM supports the finding related to the compensations: there is only interaction between government reimbursements and the number of projects in the three-player case, so that a $60 \%$ compensation for instance could give extra incentives for inexperienced players to refrain from investing less when a new project was introduced. Consequently, compensations get a second feature: not only do they level the playing field, but they also inhibit decreasing the ex ante investment in the dynamic case. Moreover, the extra expenses that result from the reimbursements are compensated through the increased price competition in the multi-project setting.

In this vein, Table 6 reports the difference between the total expected government cost of the two-project pipeline and the total expected government cost in the case a single project is tendered two times consecutively. In order to make a valid comparison and to translate the single-project government cost into one that is equivalent to the two-project logic, two intermediate results have been developed. For the first project, the initial sub-game is represented by $\left(e_{1}, e_{2}, e_{3}\right)$ and the government cost is calculated. For tendering a second project without a former pipeline, three scenarios might have occurred: $\left(e_{1}^{\prime}, e_{2}, e_{3}\right),\left(e_{1}, e_{2}^{\prime}, e_{3}\right)$ or $\left(e_{1}, e_{2}, e_{3}^{\prime}\right)$, for which the prime indicates the updated experience level for the player who has previously won. For the worst case method, the expected government cost of the most expensive sub-game is discounted and added to the cost of the previous project, while for the weighted method an equal probability is attributed to each sub-game. The expected government cost is significantly lower if there is a project pipeline, regardless of the project risk or the number of players. The absolute values of the differences are greater in the two-player case, especially for risky projects. On the 
contrary, it are the less risky projects that have a greater contribution to the government cost decrease in the three-player situation.

\begin{tabular}{|c|c|c|c|}
\hline VSM & $\gamma_{i}$ & $\begin{array}{c}\text { Worst case } \\
\text { method }\end{array}$ & $\begin{array}{l}\text { Weighted } \\
\text { method }\end{array}$ \\
\hline \multirow{3}{*}{2 players } & 0.10 & $\begin{array}{c}-36,345 * * * \\
\left(1.67 * 10^{-6}\right)\end{array}$ & $\begin{array}{l}-27,946^{* * *} * \\
\left(4.77 * 10^{-6}\right)\end{array}$ \\
\hline & 0.20 & $\begin{array}{l}-69,922 * * * \\
\left(7.43 * 10^{-9}\right)\end{array}$ & $\begin{array}{c}-58,436^{* * *} * \\
\left(2.36 * 10^{-8}\right)\end{array}$ \\
\hline & $\begin{array}{c}\text { All } \\
\text { scenarios }\end{array}$ & $\begin{array}{l}-49,633^{* * *} * \\
\left(3.16^{*} 10^{-13}\right)\end{array}$ & $\begin{array}{l}-43,191 * * * \\
\left(9.69 * 10^{-12}\right)\end{array}$ \\
\hline \multirow{3}{*}{3 players } & 0.10 & $\begin{array}{l}-28,282^{* * * *} \\
\left(2.58 * 10^{-15}\right)\end{array}$ & $\begin{array}{l}-26,026^{* * *} \\
\left(7.01 * 10^{-14}\right)\end{array}$ \\
\hline & 0.20 & $\begin{array}{l}-8,326^{* * *} \\
\left(1.64 * 10^{-6}\right)\end{array}$ & $\begin{array}{c}-4,172 * * * \\
(0.0037)\end{array}$ \\
\hline & $\begin{array}{c}\text { All } \\
\text { scenarios }\end{array}$ & $\begin{array}{l}-18,304 * * * \\
\left(<2.2 * 10^{-16}\right)\end{array}$ & $\begin{array}{l}-15,099 * * * \\
\left(1.82 * 10^{-13}\right)\end{array}$ \\
\hline
\end{tabular}

Table 6: Absolute differences and associated p-values in tendering two times a single project or in the case of a two-project pipeline.

\subsection{Parameter sensitivity analysis for the VSM}

The base case analysis allows one to closely look into particular governmental policies, but this section focuses on a sensitivity analysis of the model parameters as shown in Table 2 and extends the single-project results of De Clerck and Demeulemeester (2014). The optimal strategy that results from the VSM consists of the ex ante budgeted investment choices and mark-up choices for all the projects in the pipeline.

\subsubsection{Within-strategy dynamics}

Table 7 reports the dynamics within the optimal strategy and summarizes the average differences between the investment willingness percentages and the required mark-up for the first and the second project in the pipeline. The scenario-by-scenario comparison in the twoplayer case concludes that the ex ante investment percentages are higher for the first project than for the second project. This means that a contractor believes that, on average, he will have to invest less in the second project than for the first project. Conditioning on the experience levels could not guarantee significant results for all the levels. Moving towards three shortlisted bidders, a small significance is attributed to the opposite finding, but for the majority of experience levels, neither the paired t-test, nor the Wilcoxon signed-rank test proves significant ex ante differences. On the contrary, the mark-up dynamics are more outspoken. For both the two-player case as well as the three-player case, the optimal mark-up is expected to be set significantly higher for the second project than for the first project. 


\begin{tabular}{|c|c|c|c|c|c|c|}
\hline VSM & & 2 players & & & 3 players & \\
\hline $\begin{array}{l}\text { Measured difference } \\
\qquad(Z=2)\end{array}$ & $\begin{array}{c}\text { Absolute } \\
\text { mean value of } \\
\text { the difference } \\
\Delta(\text { in } \%)\end{array}$ & $\begin{array}{c}\text { Paired t-test } \\
\text { p-value of } \\
H_{0}: \Delta=0\end{array}$ & $\begin{array}{l}\text { Wilcoxon } \\
\text { signed-rank } \\
\text { p-value }\end{array}$ & $\begin{array}{c}\text { Absolute } \\
\text { mean value of } \\
\text { the difference } \\
\Delta(\text { in } \%)\end{array}$ & $\begin{array}{c}\text { Paired t-test } \\
\text { p-value of } \\
H_{0}: \Delta=0\end{array}$ & $\begin{array}{l}\text { Wilcoxon } \\
\text { signed-rank } \\
\text { p-value }\end{array}$ \\
\hline$i_{2}^{a v g}\left(s_{1}^{*}\right)-i_{1}^{a v g}\left(s_{1}^{*}\right)$ & $-0.0671 * *$ & 0.0272 & 0.0273 & $0.0251 *$ & 0.0945 & 0.0937 \\
\hline $\mid e_{1}=0$ & $-0.1458^{*}$ & 0.0623 & 0.0631 & $0.0595^{*}$ & 0.0548 & 0.0546 \\
\hline $\mid e_{1}=2$ & -0.0486 & 0.5112 & 0.5113 & 0.0258 & 0.4917 & 0.4968 \\
\hline$e_{1}=4$ & -0.0694 & 0.3412 & 0.3413 & $0.0694^{*}$ & 0.0662 & 0.0659 \\
\hline$e_{1}=6$ & $-0.2014 * * *$ & 0.0057 & 0.0059 & 0.0119 & 0.7465 & 0.7454 \\
\hline $\mid e_{1}=8$ & 0 & 1 & 1 & -0.0198 & 0.6110 & 0.6126 \\
\hline$e_{1}=10$ & 0.0625 & 0.4142 & 0.4137 & 0.0040 & 0.9175 & 0.9172 \\
\hline$m_{2}^{a v g}\left(s_{1}^{*}\right)-m_{1}^{a v g}\left(s_{1}^{*}\right)$ & $1.4757 * * *$ & $<2.2 * 10^{-16}$ & $<2.2 * 10^{-16}$ & $0.6134 * * *$ & $<2.2 * 10^{-16}$ & $<2.2 * 10^{-16}$ \\
\hline $\mid e_{1}=0$ & $2.5347 * * *$ & $<2.2 * 10^{-16}$ & $5.13 * 10^{-16}$ & $0.6448 * * *$ & 0.0069 & 0.0065 \\
\hline$e_{1}=2$ & $1.8403 * * *$ & $8.02 * 10^{-10}$ & $2.52 * 10^{-9}$ & $0.8929 * * *$ & $1.58 * 10^{-5}$ & $5.90 * 10^{-7}$ \\
\hline$e_{1}=4$ & $1.2153 * * *$ & $1.07 * 10^{-5}$ & $1.44 * 10^{-5}$ & $0.7540 * * *$ & $1.88 * 10^{-5}$ & $1.99 * 10^{-6}$ \\
\hline$e_{1}=6$ & $0.9375 * * *$ & 0.0002 & 0.0003 & $0.4464 * * *$ & 0.0009 & 0.0005 \\
\hline$e_{1}=8$ & $1.2500 * * *$ & $1.28 * 10^{-5}$ & $1.71 * 10^{-5}$ & $0.4167 * * *$ & 0.0018 & 0.0010 \\
\hline$e_{1}=10$ & $1.0764 * * *$ & 0.0003 & 0.003 & $0.5258 * * *$ & $9.89 * 10^{-6}$ & $5.19 * 10^{-6}$ \\
\hline
\end{tabular}

Table 7: Average differences in the investment and mark-up choices within the optimal strategy for the two-project pipeline.

\subsubsection{First-project comparison}

More interestingly, Table 8 reports the results of the scenario-specific differences between the preferred pre-tender investment level and the mark-up level for the first project in the two-project environment and the single-project environment respectively. The average results over all scenarios are highly significant for the mark-up. The mark-ups of the first project drop considerably when a second project is introduced in both the two- as well as the three-player situation, with an average decrease of $2.40 \%$ and $1.05 \%$ respectively. For both cases, the absolute impact is greater for inexperienced players than for more experienced ones. Looking at the investment levels, the statistical tests confirm that pre-tender investments ought to be higher when a second project is added to the pipeline. For the three-player case, no significant overall impact could be shown, but inexperienced players will now invest less than when the government has no project agenda. This might be explained through the fact that contractors will spread the investment efforts more over the pipeline of projects. Nevertheless, a comparison of the results of the average investment percentage and mark-up percentage with the choices in the case that there is no pipeline did only support the mark-up drop (-1.7\% in the two-player case and $-0.7 \%$ in the three-player case), while the average investment over the pipeline is only significantly higher for the two-player case $(+0.1 \%)$. The average pay-off expectation per project 
drops with $€ 5,137$ in the two-player environment and with $€ 2,221$ in the three-player case according to the simulation.

\begin{tabular}{|c|c|c|c|c|c|c|c|}
\hline \multirow[t]{2}{*}{ VSM } & & \multicolumn{3}{|c|}{2 players } & \multicolumn{3}{|c|}{3 players } \\
\hline & $\begin{array}{c}\text { Measured } \\
\text { difference } \\
\text { w.r.t. } Z=1\end{array}$ & $\begin{array}{l}\text { Absolute mean } \\
\text { value of the } \\
\text { difference } \Delta \\
\text { (in } \%)\end{array}$ & $\begin{array}{c}\text { Paired t-test } \\
\text { p-value of } \\
H_{0}: \Delta=0\end{array}$ & $\begin{array}{c}\text { Wilcoxon } \\
\text { signed-rank } \\
\text { p-value }\end{array}$ & $\begin{array}{c}\text { Absolute } \\
\text { mean value of } \\
\text { the difference } \\
\Delta(\text { in } \%)\end{array}$ & $\begin{array}{c}\text { Paired t-test } \\
\text { p-value of } \\
H_{0}: \Delta=0\end{array}$ & $\begin{array}{c}\text { Wilcoxon } \\
\text { signed-rank } \\
\text { p-value }\end{array}$ \\
\hline \multirow{7}{*}{ Investment } & All scenarios & $0.1585 * * *$ & $3.76 * 10^{-8}$ & $4.35^{*} 10^{-8}$ & -0.0073 & 0.6178 & 0.6013 \\
\hline & $e_{1}=0$ & $0.3194 * * *$ & $8.57 * 10^{-6}$ & $1.16^{*} 10^{-5}$ & $-0.1012 * * *$ & 0.0018 & 0.0018 \\
\hline & $e_{1}=2$ & $0.2222 * * *$ & 0.0011 & 0.0012 & $-0.0893 * *$ & 0.0181 & 0.0184 \\
\hline & $e_{1}=4$ & 0.0347 & 0.6125 & 0.6122 & -0.0079 & 0.8210 & 0.8078 \\
\hline & $e_{1}=6$ & $0.2153 * * *$ & 0.0037 & 0.0039 & 0.0060 & 0.8687 & 0.8738 \\
\hline & $e_{1}=8$ & 0.0278 & 0.6956 & 0.6952 & $0.1052 * * *$ & 0.0047 & 0.0049 \\
\hline & $e_{1}=10$ & $0.1319^{*}$ & 0.0586 & 0.0596 & 0.0437 & 0.2189 & 0.2215 \\
\hline \multirow{7}{*}{ Mark-up } & All scenarios & $-2.4016^{* * * *}$ & $<2.2 * 10^{-16}$ & $<2.2 * 10^{-16}$ & $-1.0516^{* * *}$ & $<2.2 * 10^{-16}$ & $<2.2 * 10^{-16}$ \\
\hline & $e_{1}=0$ & $-3.5069 * * *$ & $<2.2 * 10^{-16}$ & $<2.2 * 10^{-16}$ & $-1.3988 * * *$ & $9.89 * 10^{-8}$ & $1.10^{*} 10^{-7}$ \\
\hline & $e_{1}=2$ & $-2.3958 * * *$ & $<2.2 * 10^{-16}$ & $6.88 * 10^{-16}$ & $-1.2401 * * *$ & $1.91 * 10^{-7}$ & $3.16^{*} 10^{-9}$ \\
\hline & $e_{1}=4$ & $-2.3264 * * *$ & $2.10 * 10^{-15}$ & $4.87 * 10^{-14}$ & $-1.0417 * * *$ & $4.87 * 10^{-9}$ & $1.01 * 10^{-10}$ \\
\hline & $e_{1}=6$ & $-2.2222 * * *$ & $1.31 * 10^{-14}$ & $2.17 * 10^{-13}$ & $-0.9722 * * *$ & $3.97 * 10^{-12}$ & $5.19 * 10^{-13}$ \\
\hline & $e_{1}=8$ & $-2.2917 * * *$ & $9.29 * 10^{-15}$ & $1.63 * 10^{-13}$ & $-0.7440 * * *$ & $7.53 * 10^{-9}$ & $4.66^{*} 10^{-10}$ \\
\hline & $e_{1}=10$ & $-1.6667 * * *$ & $3.93 * 10^{-8}$ & $8.16^{*} 10^{-8}$ & $-0.9127 * * *$ & $1.88 * 10^{-15}$ & $7.46^{*} 10^{-16}$ \\
\hline
\end{tabular}

Table 8: Differences between the investment and mark-up choice for the first project of a two-project pipeline and the choices in a single-project environment.

The previous results consider the entire dataset over all scenarios, but a sensitivity analysis that compares the scenarios, helps to better understand the parameter dependency of the findings. The ANOVA output in Appendix reveals the sensitivity results. Both tables compare the difference in the investment and mark-up levels for the first project in a single-project and a twoproject environment for the two- and three-player case respectively. A look into the main effects reveals that the bidding behavior responds differently to the introduction of a second project for the two- and three- player case.

\subsubsection{Project complexity}

Table 9 digs into the project complexity in the two-player setting. Omitting interaction effects, projects with a limited complexity and that do not require a lot of research $\left(\gamma_{i}=0.05\right)$ incur a significant increase of $0.25 \%\left(\mathrm{p}=9.6^{*} 10^{-6}\right)$ in the investment willingness. The increase in investment willingness drops to $0.18 \%\left(\mathrm{p}=2.6^{*} 10^{-4}\right)$ when the share of the variance that is related to investment rises to 0.10 . In the cases for which $\gamma_{i}$ reaches 0.20 , the investment willingness is not significantly influenced by one extra project. In the two-player case, the mark-up results are also significantly related to the project's complexity. Mark-ups for project categories with larger 
risk features drop more, ceteris paribus. Interestingly, Figure 2 shows that the mark-up for the first project has become increasing in the experience level in the two-project setting, while it was relatively stable in the single-project setting. Especially for complex projects, experienced players require higher mark-ups than their inexperienced counterparts.

\begin{tabular}{|c|c|c|c|c|c|c|}
\hline $\begin{array}{c}\text { VSM } \\
2 \text { players } \\
\end{array}$ & \multicolumn{3}{|c|}{ Investment } & \multicolumn{3}{|c|}{ Mark-up } \\
\hline $\begin{array}{c}\text { Measured } \\
\text { difference } \\
\text { w.r.t. } Z=1\end{array}$ & $\begin{array}{l}\text { Absolute } \\
\text { mean value } \\
\text { of the } \\
\text { difference } \Delta \\
\text { (in } \% \text { ) }\end{array}$ & $\begin{array}{c}\text { Paired t-test } \\
\text { p-value of } \\
H_{0}: \Delta=0\end{array}$ & $\begin{array}{l}\text { Wilcoxon } \\
\text { signed-rank } \\
\text { p-value }\end{array}$ & $\begin{array}{c}\text { Absolute } \\
\text { mean value } \\
\text { of the } \\
\text { difference } \Delta \\
\text { (in } \% \text { ) }\end{array}$ & $\begin{array}{c}\text { Paired t-test } \\
\text { p-value of } \\
H_{0}: \Delta=0\end{array}$ & $\begin{array}{l}\text { Wilcoxon } \\
\text { signed-rank } \\
\text { p-value }\end{array}$ \\
\hline$\gamma_{i}=0.05$ & $0.2500 * * *$ & $9.65 * 10^{-7}$ & $1.27 * 10^{-7}$ & $-0.8854 * * *$ & $2.29 * 10^{-12}$ & $6.33 * 10^{-12}$ \\
\hline$\gamma_{i}=0.10$ & $0.1771 * * *$ & 0.0002 & 0.0003 & $-2.2569 * * *$ & $<2.2 * 10^{-16}$ & $<2.2 * 10^{-16}$ \\
\hline$\gamma_{i}=0.20$ & 0.0486 & 0.3321 & 0.3318 & $-4.0625 * * *$ & $<2.2 * 10^{-16}$ & $<2.2 * 10^{-16}$ \\
\hline
\end{tabular}

Table 9: Ceteris paribus sensitivity results for project complexity in a two-player case with the difference in investment and mark-up percentages between a two-project setting and a single-project setting.

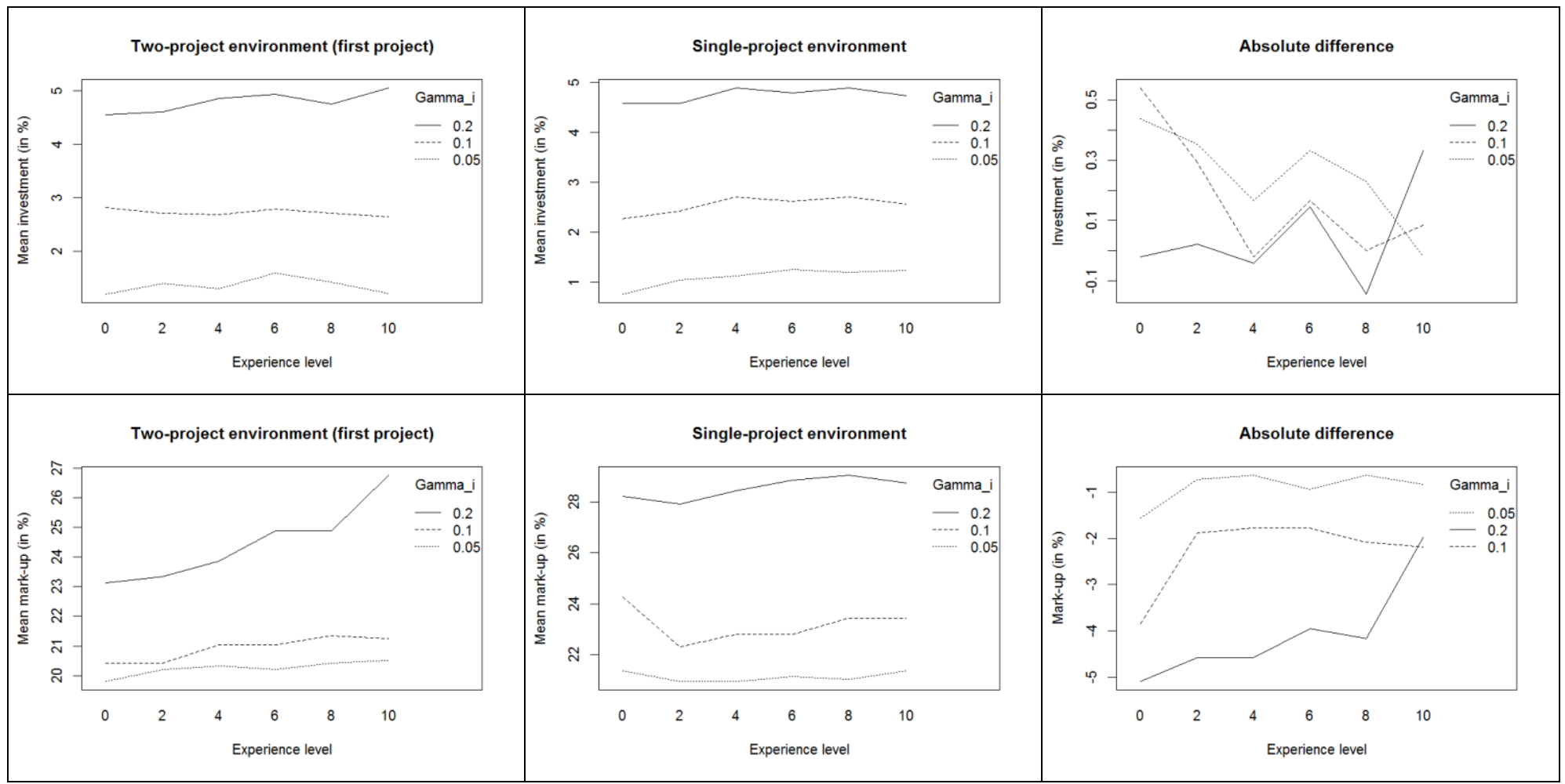

Figure 2: Interaction plots of project complexity and the experience level in the two-player setting with independent variable the choices for the first project in a two-project pipeline (left), the single-project strategy (middle) and their difference (right).

This differs from the three-player setting of Figure 3 in which the downward mark-up trend for increasing experience levels remains. When the impact of the knowledge parameter $\gamma_{i}$ is studied in a three-player environment, the investments are only significantly raised for projects 
of medium complexity and once projects become too risky, the introduction of an extra project results in a drop $(0.09 \%$ on average) of the investment willingness and no significant drops in mark-ups are apparent. However, for lower risk projects, the mark-up impact is largest, especially for inexperienced players.
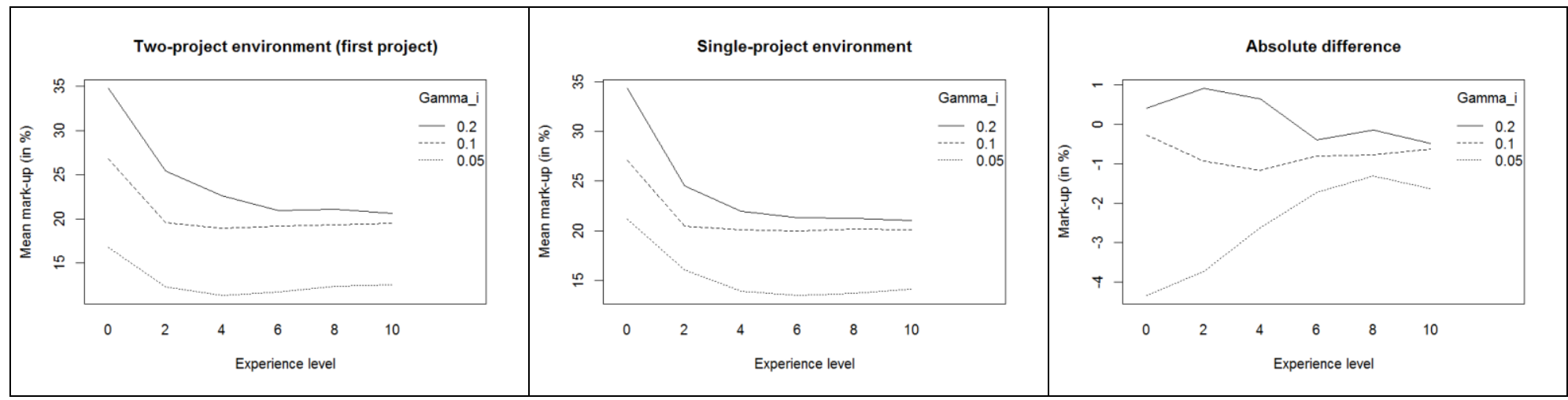

Figure 3: Interaction plots of project complexity and the experience level in the three-player setting with independent variable the mark-up choice for the first project in a two-project pipeline (left), the singleproject strategy (middle) and their difference (right).

\begin{tabular}{ccccccc}
\hline $\begin{array}{c}\text { VSM } \\
\text { players }\end{array}$ & \multicolumn{3}{c}{ Investment } & \multicolumn{3}{c}{ Mark-up } \\
\hline $\begin{array}{c}\text { Measured } \\
\text { difference } \\
\text { w.r.t. } Z=1\end{array}$ & $\begin{array}{c}\text { Absolute } \\
\text { mean value } \\
\text { of the } \\
\text { difference } \Delta \\
\text { (in \%) }\end{array}$ & $\begin{array}{c}\text { Paired t-test } \\
\text { p-value of } \\
H_{0}: \Delta=0\end{array}$ & $\begin{array}{c}\text { Wilcoxon } \\
\text { signed-rank } \\
\text { p-value }\end{array}$ & $\begin{array}{c}\text { Absolute } \\
\text { mean value } \\
\text { of the } \\
\text { difference } \Delta \\
\text { in \%) }\end{array}$ & $\begin{array}{c}\text { Paired t-test } \\
\text { p-value of } \\
H_{0}: \Delta=0\end{array}$ & $\begin{array}{c}\text { Wilcoxon } \\
\text { signed-rank } \\
\text { p-value }\end{array}$ \\
\hline$\gamma_{i}=0.05$ & 0.0228 & 0.2954 & 0.3074 & $-2.5595^{* * *}$ & $<2.2^{*} 10^{-16}$ & $<2.2^{*} 10^{-16}$ \\
\hline$\gamma_{i}=0.10$ & $0.0466^{*}$ & 0.0663 & 0.0665 & $-0.7589^{* * *}$ & $<2.2^{*} 10^{-16}$ & $2.91^{*} 10^{-16}$ \\
\hline$\gamma_{i}=0.20$ & $-0.0913^{* * *}$ & 0.0012 & 0.0012 & 0.1637 & 0.3274 & 0.2635 \\
\hline$d=0$ & 0.0450 & 0.1019 & 0.1063 & $-0.8399^{* * *}$ & $9.26^{*} 10^{-6}$ & $1.77^{*} 10^{-6}$ \\
\hline$d=0.30$ & -0.0225 & 0.3973 & 0.3854 & $-0.4034^{* *}$ & 0.0131 & 0.0030 \\
\hline$d=0.60$ & $0.0608^{* *}$ & 0.0428 & 0.0429 & $-1.3228^{* * *}$ & $<2.2^{*} 10^{-16}$ & $<2.2-10^{-16}$ \\
\hline$d=0.90$ & $-0.1124 * * *$ & 0.0005 & 0.0005 & $-1.6402^{* * *}$ & $<2.2^{*} 10^{-16}$ & $<2.2 * 10^{-16}$ \\
\hline
\end{tabular}

Table 10: Ceteris paribus sensitivity results for project complexity and government compensation in a three-player case with the difference in investment and mark-up percentages between a two-project setting and a single-project setting.

\subsubsection{Government compensation}

As the bidding behavior is rather levelled, the government compensation is not necessary to increase competition in the case where two bidders are shortlisted for a single project. Increasing the number of projects in the pipeline does not modify the dynamics. The introduction of a second project automatically triggers fiercer competition and less experienced players lower the mark-ups, that now converge towards the mark-ups of the incumbents. 
In the three-player setting with one project, government compensations are a helpful tool to increase competition. Table 10 suggests that the effect of government compensations is influenced by the introduction of a second project in the pipeline. Although only a limited number of compensation levels have been tested, a $60 \%$ compensation will for instance result in a $0.06 \%$ higher investment level and a $1.32 \%$ lower mark-up, relative to its respective singleproject scenario.

\subsubsection{Hypotheses}

In conclusion, it is necessary to look how the hypotheses are backed up by the experimental findings. Unfortunately, the model could not provide a definite answer for Hypothesis 1. The VSM for the two-player case slightly supports the investment increase, but no investment change has been identified in the three-player case. However, all models support Hypothesis 2. A pipeline does have a beneficial impact on the mark-up, which also results in lower procurement costs for the government (Hypothesis 6). The variation within the ex ante strategy (Hypothesis 3) was supported for the mark-ups, but only limited evidence could be given for the investments. A similar conclusion is reached for Hypothesis 4: markets become more competitive from a markup perspective when more projects are introduced, but it does not necessarily serve as a mechanism to level the playing field in a multi-player case. Therefore, government compensations could still help in three-player settings with complex projects to increase the competition (Hypothesis 5).

\section{Discussion}

\begin{tabular}{llc}
\hline Respondent & Function & Region of expertise \\
\hline $\mathrm{A}$ & Partnerships Victoria & Victoria (Australia) \\
\hline $\mathrm{B}$ & Executive director of investment company & $\begin{array}{c}\text { Australia and other developed } \\
\text { countries }\end{array}$ \\
\hline $\mathrm{C}$ & $\begin{array}{l}\text { Advisor in research and advisory institution for } \\
\text { construction sector }\end{array}$ & Belgium \\
\hline $\mathrm{D}$ & Construction lawyer & Australia \\
\hline $\mathrm{E}$ & Independent PPP consultant & South Africa \\
\hline $\mathrm{F}$ & Independent PPP consultant & Czech Republic \\
\hline $\mathrm{G}$ & Partner at consultancy firm & Australia \\
\hline $\mathrm{H}$ & Independent legal PPP consultant & Europe \\
\hline
\end{tabular}

Table 11: List of respondents

Table 11 lists the profile of some of the respondents that have been interviewed to give their view on the modeling and theoretical impact of a pipeline introduction. Markets significantly differ in their respective pipelines. Canada has a reputation of keeping the market going, while 
the pipeline of the Private Finance Initiative in the UK dropped off (respondent B). In Australia, the state Victoria tries to maintain a pipeline and communicates the prospects of future opportunities when projects are launched, under the belief that a strong pipeline results in new competition and higher investments (respondents A, D). Respondents C and E, on the other hand, claim that it is not always evident to have a continuity of projects due to the longevity and the magnitude of the budgetary requirements. Finally, respondent F claims that the number of projects should not exceed market capacity. All respondents were in favor of a project pipeline. According to the respondents, but not entirely supported by the theoretical findings, a first advantage is that it results in more investments in initial projects and that the total investment is spread over different projects (respondent D). The private sector is willing to invest more in nonproject fixed costs and better plan its financial strategy (respondent F) and human resources can be employed for a longer time (respondent D). The experience of respondent A learned that consortia recently have a more consistent structure, apart from the financial partner. Moreover, the government benefits from a pipeline because of the increased competition and the lower procurement cost which is in line with the experimental findings. The increased competition puts of course a ceiling on the contractors' profits (respondent B). Another downside is the danger of the "lazy Susan" approach in established markets: the work goes around and might be attributed to the desperate contractor (respondent B). Often consortia are not substantial enough to carry out more than two projects at the same time, so governments need to be conscious about the magnitude of the project and about spreading the work (respondent B, D).

The respondents expect more competition and the majority expects higher investments in the initial projects. Consequently, all respondents explicitly favor a long-term project pipeline over short-term bid cost compensations. Respondent $\mathrm{H}$ stipulates that pipelines will be better to attract overseas contractors, but respondents $\mathrm{A}$ and $\mathrm{B}$ claim that the pipeline should be visible and trustworthy. Nevertheless, some respondents believe in the applicability of compensations. Firstly, it could be necessary if it is impossible to attract two bidders or when important informational or innovative added value can be created (respondents A,D). In this vein, compensations create a larger pool of capital (respondent D). Nevertheless, respondent G fears the undue difference in the treatment of bidders, so that strict limitations and guidelines are necessary. Last but not least, respondents $\mathrm{D}$ and $\mathrm{H}$ put forward that governments should first attempt to decrease the bidding costs. 


\section{Conclusion}

This paper presents the results of a theoretical study of the PPP procurement mechanism. More particularly, it assessed how contractors change their ex ante bidding strategy in the case a pipeline of projects is introduced. The tendering processes are time-consuming and often overlapping, so contractors will make an initial budget how to spread their bidding efforts over the different stages of the game, in the belief that experience of winning a project will benefit the competitive position in later tenders. The mechanism has been translated in an analytical auction procurement framework for which a computerized experiment has been developed to identify the Bayesian Nash equilibrium. The introduction of extra projects mainly has a mark-up impact and consequently reduces the expected government procurement cost. Consequently, from a government perspective and besides from cementing the project agenda, it might also be beneficial to split up large projects into smaller parts as long as there are no coordination issues.

The model could not support the hypothesis that contractors will put more effort in the bid preparation. Instead, contractors take the expected profits of an experiential gain into account for the ex ante strategy determination and therefore directly increase the probability of winning by decreasing the mark-up for initial projects. Especially in three- and four-player markets, appropriate incentives are necessary to assure competitive forces. In this way, they prevent the market to become saturated or that mature players become too comfortable with their competitive advantage. Therefore, governments should first try to reduce bidding costs that add no value, like excessive design requirements or lengthy negotiation processes. Moreover, they should reward bidders who have invested more in research. If necessary, bid compensations could trigger additional investment incentives.

This study has important limitations. Firstly, marginal effects could not be revealed because of the discretization of strategies. Moreover, the study relies on approximate equilibria and simulation outcomes. This leads to a lot of flexibility but prevents us from arriving at closedform analytical expressions. Moreover, empirical data would highly assist in shaping the distributions, but are hard to obtain in the competitive PPP market where high values are at stake. Future research could look into the strictly sequential model, where projects are tendered consecutively and consortia may change strategies with respect to the current state of the game. The relaxation of the assumption that investments are project-specific and the possibility of randomly arriving bidders could be investigated. In that case, pre-tender investments may 
contribute to the knowledge base of future projects. Ultimately, the practical applicability could benefit from the introduction of capacity constraints. Furthermore, this cutting-edge procurement application offers new challenging research opportunities for the mathematical and experimental auction field.

\section{Acknowledgement}

The authors would like to express their gratitude towards the Intercollegiate Center for Management Science (Brussels) for the financial support of this research project. Moreover, we would like to mention the highly appreciated hospitality of Prof. Mervyn Lewis and the University of South Australia. Finally, we are grateful for the valuable feedback of the practitioners from the field who have shared their thoughts.

References

Aissaoui N, Haouari M, Hassini E (2007) Supplier selection and order lot sizing modeling: a review. Computers \& Operations Research 34 3516-3540.

Anton JJ, Yao DA (1987) Second sourcing and the experience curve: price competition in defense procurement. RAND Journal of Economics 18 57-76.

Arozamena L, Cantillon E (2002) Investment incentives in procurement auctions. Review of Economic Studies 71 1-18.

Benoit JP, Krishna V (2001) Multiple-object auctions with budget constrained bidders. Review of Economic Studies 68 155-180.

Branco F (1997) Sequential auctions with synergies: an example. Economics Letters 54 159163.

Brosig J, Rei $\beta$ JP (2007) Entry decisions and bidding behavior in sequential first-price procurement auctions: an experimental study. Games and Economic Behavior 58 50-74.

Cai G, Wurman PR (2005) Monte Carlo approximation in incomplete information, sequential auction games. Decision Support Systems 39 153-168.

Carrillo P, Robinson H, Foale P, Anumba C, Bouchlaghem D (2008) Participation, barriers and opportunities in PFI: The United Kingdom experience. Journal of Management in Engineering 24 138-145. 
Cason TN, Kannan KN, Siebert R (2011) An experimental study of information revelation policies in sequential auctions. Management Science 57 667-688.

Catalán J, Epstein R, Guajardo M, Yung D, Martínez C (2009) solving multiple scenarios in a combinatorial auction. Computers \& Operations Research 36 2752-2758.

Chen C, Doloi H (2008) BOT application in China: Driving and impeding factors. International Journal of Project Management 26 388-398.

Conitzer V, Sandholm T (2003) Complexity results about Nash equilibria. In Proceedings of the $18^{\text {th }}$ International Joint Conference on Artificial Intelligence (IJCAI-03), Acapulco, Mexico, 765-771.

Daskalakis C, Goldberg P, Papadimitriou C (2006) The complexity of computing a Nash equilibrium. In Proceedings of the $38^{\text {th }}$ annual ACM symposium on Theory of Computing (STOC-06), Seattle, Washington, USA, 71-78.

De Clerck D, Demeulemeester E (2014) Towards a more competitive PPP procurement market: a game-theoretical analysis. FEB Research Report KBI_1408, KU Leuven - Faculty of Economics and Business, Leuven, Belgium, 59pp.

De Silva DG, Jeitschko TD, Kosmopoulou G (2005) Stochastic synergies in sequential auctions. International Journal of Industrial Organization 23 183-201.

de Vries S, Vohra R (2003) Combinatorial auctions: a survey. INFORMS Journal on Computing 15 284-309.

El Otmani S, Maul A (2009) Probability distributions arising from nested Gaussians. Comptes Rendus Mathématique 347 201-204.

Elmaghraby W (2003) The importance of ordering sequential auctions. Management Science 49 673-682.

Engelbrecht-Wiggans R (1994) Sequential auctions of stochastically equivalent objects. Economics Letters 44 87-90.

Farnia F, Frayret JM, LeBel L, Beaudry C (2013) Multiple-round timber auction design and simulation. International Journal of Production Economics 146 129-141.

Friedman L (1956) A competitive bidding strategy. Operations Research 4 104-112.

Ho SP (2008) Government policy on PPP financial issues: bid compensation and financial renegotiation. In A. Akintoye, M. Beck, eds., Policy, Finance \& Management for Public-Private Partnerships (Willey-Blackwell, Oxford, U.K.), 267-300. 
Hörner J, Jamison J (2008) Sequential common-value auctions with asymmetrically informed bidders. Review of Economic Studies 75 475-498.

Jeitschko TD (1999) Equilibrium price paths in sequential auctions with stochastic supply. Economics Letters 64 67-72.

Jofre-Bonet M, Pesendorfer M (2003) Estimation of a dynamic auction game. Econometrica 71 1443-1489.

Jofre-Bonet M, Pesendorfer M (2014) Optimal sequential auctions. International Journal of Industrial Organization 33 61-71.

Katzman B (1999) A two stage sequential auction with multi-unit demands. Journal of Economic Theory 86 77-99.

Katehakis MN, Puranam KS (2012) On bidding for a fixed number of items in a sequence of auctions. European Journal of Operational Research 222 76-84.

King M, Mercer A (1988) Recurrent competitive bidding. European Journal of Operational Research 33 2-16.

King M, Mercer A (1990) The optimum markup when bidding with uncertain costs. European Journal of Operational Research 47 348-363.

Kostamis D, Beil DR, Duenyas I (2009) Total-cost procurement auctions: Impact of suppliers' cost adjustments on auction form and choice. Management Science 55 1985-1999.

KPMG (2010) PPP procurement: Review of barriers to competition and efficiency in the procurement of PPP projects. KPMG Corporate Finance (aust) Pty Ltd, 65pp.

Lippman SA, McCardle KF, Tang CS (2013) Using Nash bargaining to design project management contracts under uncertainty. International Journal of Production Economics 145 199-207.

Martzoukos SH, Zacharias E (2013) Real option games with R\&D and learning spillovers. Omega 41 236-249.

Maskin E, Riley J (2000) Asymmetric auctions. Review of Economic Studies 67 413-438.

Menezes FM, Monteiro PK (2004) Auctions with synergies and asymmetric buyers. Economics Letters 85 287-294.

Mehlenbacher A (2007) Multiagent system platform for auction experiments. Economics Department Discussion Paper DDP0706, University of Victoria, Victoria, Canada, 28pp. 
Milgrom P, Weber R (1982) A theory of auctions and competitive bidding. Econometrica 50 1089-1122.

Naert PA, Weverbergh M (1978) Cost uncertainty in competitive bidding models. Journal of the Operational Research Society 29 361-372.

Olivares M, Weintraub GY, Epstein R, Yung D (2012) Combinatorial auctions for procurement: an empirical study of the Chilean school meals auction. Management Science 58 1458-1481.

Oo BL, Drew DS, Lo HP (2010) Modeling the heterogeneity in contractors' mark-up behavior. Journal of Construction Engineering and Management 136 720-729.

Oren SS, Rothkopf MH (1975) Optimal bidding in sequential auctions. Operations Research 23 1080-1090.

Pekeč A, Rothkopf MH (2003) Combinatorial auction design. Management Science $491485-$ 1503.

Pitchik C (2009) Budget-constrained sequential auctions with incomplete information. Games and Economic Behavior 66 928-949.

Rei $\beta$ JP, Schöndube JR (2010) First-price equilibrium and revenue equivalence in a sequential procurement auction model. Journal of Economic Theory 43 99-141.

Rothkopf MH, Harstad RM, Fu Y (2003) Is subsidizing inefficient bidders actually costly? Management Science 49 71-84.

Said M (2011) Sequential auctions with randomly arriving buyers. Games and Economic Behavior 73 236-243.

Takano Y, Ishii N, Muraki M (2014) A sequential competitive bidding strategy considering inaccurate cost estimates. Omega 42 132-140.

Triki C, Beraldi P, Gross G (2005) Optimal capacity allocation in multi-auction electricity markets under uncertainty. Computers \& Operations Research 32 201-217.

Triki C, Oprea S, Beraldi P, Crainic TG (2014) The stochastic bid generation problem in combinatorial transportation auctions. European Journal of Operational Research 991-999.

Von der Fehr NHM (1994) Predatory bidding in sequential bidding. Oxford Economic Papers $46345-356$. 
Weber RJ (1983) Multiple-object auctions. In R. Engelbrecht-Wiggans, M. Shubik, R.M. Sterk, eds., Auctions, bidding, and contracting: Uses and theory (New York University Press) $165-191$.

Wolfram CD (1998) Strategic bidding in a multi-unit auction: an empirical analysis of bids to supply electricity in England and Wales. RAND Journal of Economics 29 703-725.

Yildirim H (2004) Piecewise procurement of a large-scale project. International Journal of Industrial Organization 22 1349-1375.

Zeithammer R (2007) Research note - Strategic bid-shading and sequential auctioning with learning from past prices. Management Science 53 1510-1519.

Zeithammer R (2009) Commitment in sequential auctioning: advance listings and threshold prices. Journal of Economic Theory 38 187-216.

Appendix: ANOVA output of experimental results

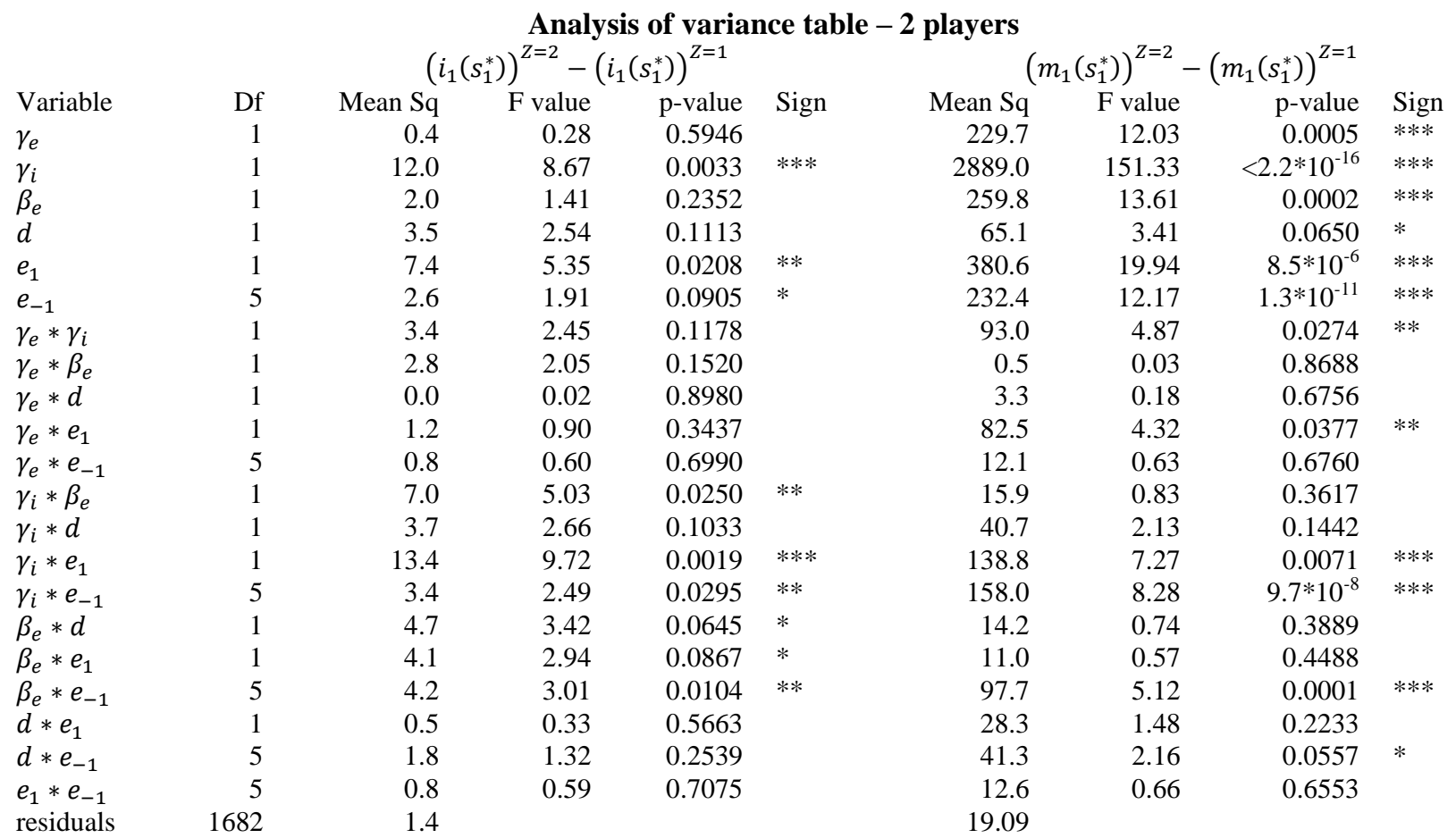

Table A.1: ANOVA output for the differences in the investment and mark-up choices for the first project in a two-project setting with respect to a single-project setting. 


\begin{tabular}{|c|c|c|c|c|c|c|c|c|c|}
\hline \multirow[b]{2}{*}{ Variable } & & & )$^{Z=2}-$ & $\begin{array}{l}\text { is of varia } \\
\left.\left.s_{1}^{*}\right)\right)^{Z=1}\end{array}$ & ce tab & layers & $\left.\left.s_{1}^{*}\right)\right)^{Z=2}$ & $\left.n_{1}\left(s_{1}^{*}\right)\right)^{Z=1}$ & \multirow[b]{2}{*}{ Sign } \\
\hline & Df & Mean Sq & $\mathrm{F}$ value & p-value & Sign & Mean $\mathrm{Sq}$ & F value & $\mathrm{p}$-value & \\
\hline$\gamma_{e}$ & 1 & 3.4 & 2.70 & 0.1004 & & 11.2 & 0.35 & 0.5536 & \\
\hline$\gamma_{i}$ & 1 & 17.0 & 13.35 & 0.0003 & $* * *$ & 6701.1 & 210.39 & $<2.2 * 10^{-16}$ & $* * *$ \\
\hline$\beta_{e}$ & 1 & 9.8 & 7.75 & 0.0054 & $* * *$ & 222.5 & 6.99 & 0.0082 & $* *$ \\
\hline$d$ & 1 & 11.4 & 9.00 & 0.0027 & $* * *$ & 833.3 & 26.16 & $3.2 * 10^{-7}$ & $* * *$ \\
\hline$e_{1}$ & 1 & 25.1 & 19.80 & $8.8 * 10^{-6}$ & $* * *$ & 229.0 & 7.19 & 0.0073 & $* *$ \\
\hline$e_{-1}$ & 20 & 1.7 & 1.30 & 0.1638 & & 96.2 & 3.02 & $6.6^{*} 10^{-6}$ & $* * *$ \\
\hline$\gamma_{e} * \gamma_{i}$ & 1 & 0.3 & 0.21 & 0.6474 & & 139.8 & 4.39 & 0.0362 & $* *$ \\
\hline$\gamma_{e} * \beta_{e}$ & 1 & 0.0 & 0.03 & 0.8551 & & 11.2 & 0.35 & 0.5536 & \\
\hline$\gamma_{e} * d$ & 1 & 0.8 & 0.60 & 0.4380 & & 102.4 & 3.22 & 0.0730 & $*$ \\
\hline$\gamma_{e} * e_{1}$ & 1 & 1.2 & 0.93 & 0.3361 & & 34.5 & 1.08 & 0.2981 & \\
\hline$\gamma_{e} * e_{-1}$ & 20 & 0.9 & 0.70 & 0.8342 & & 30.9 & 0.97 & 0.4959 & \\
\hline$\gamma_{i} * \beta_{e}$ & 1 & 3.3 & 2.61 & 0.1061 & & 32.5 & 1.02 & 0.3121 & \\
\hline$\gamma_{i} * d$ & 1 & 14.7 & 11.53 & 0.0007 & $* * *$ & 0.1 & 0.00 & 0.9522 & \\
\hline$\gamma_{i} * e_{1}$ & 1 & 0.0 & 0.01 & 0.9189 & & 1910.3 & 59.98 & $1.1 * 10^{-14}$ & $* * *$ \\
\hline$\gamma_{i} * e_{-1}$ & 20 & 1.8 & 1.44 & 0.0909 & $*$ & 96.1 & 3.02 & $6.7 * 10^{-6}$ & $* * *$ \\
\hline$\beta_{e} * d$ & 1 & 0.1 & 0.09 & 0.7595 & & 26.8 & 0.84 & 0.3592 & \\
\hline$\beta_{e} * e_{1}$ & 1 & 0.9 & 0.71 & 0.3999 & & 0.1 & 0.00 & 0.9468 & \\
\hline$\beta_{e} * e_{-1}$ & 20 & 0.8 & 0.61 & 0.9105 & & 32.5 & 1.02 & 0.4334 & \\
\hline$d * e_{1}$ & 1 & 4.6 & 3.59 & 0.0582 & $*$ & 48.1 & 1.51 & 0.2191 & \\
\hline$d * e_{-1}$ & 20 & 1.6 & 1.28 & 0.1786 & & 93.1 & 2.92 & $1.3 * 10^{-5}$ & $* * *$ \\
\hline$e_{1} * e_{-1}$ & 20 & 1.9 & 1.53 & 0.0624 & $*$ & 46.7 & 1.47 & 0.0825 & $*$ \\
\hline residuals & 5912 & 1.3 & & & & 31.9 & & & \\
\hline
\end{tabular}

Table A.2: ANOVA output for the differences in the investment and mark-up choices for the first project in a two-project setting with respect to a single-project setting. 
FACULTY OF ECONOMICS AND BUSINESS

Naamsestraat 69 bus 3500

3000 LEUVEN, BELGIË

tel. + 3216326612

fax +3216326791

info@econ.kuleuven.be

www.econ.kuleuven.be 